\title{
Guidelines
}

\section{European Practical and Patient- Centred Guidelines for Adult Obesity Management in Primary Care}

\author{
Dominique Durrer Schutz ${ }^{a} \quad$ Luca Busetto $^{b}$ Dror Dicker ${ }^{c}$ \\ Nathalie Farpour-Lambert ${ }^{d}$ Rachel Pryke ${ }^{e}$ Hermann Toplak $^{f}$ \\ Daniel Widmerg ${ }^{\text {Volkan Yumuk }}{ }^{\mathrm{h}}$ Yves Schutz $^{\mathrm{i}}$
}

\begin{abstract}
a Service d'enseignement thérapeutique pour maladies chroniques, Département de médecine communautaire, Hôpitaux Universitaires de Genève, Genève/Eurobesitas COMs Center, Vevey, Switzerland; ${ }^{b}$ Department of Medicine, Padova University Hospital, Bariatric Unit, University of Padova, Padova, Italy; ' Internal Medicine D \& Obesity Clinic, Hasharon Hospital, Rabin Medical Centre, Sackler School of Medicine, Tel Aviv University, Tel Aviv, Israel; d'Service d'enseignement thérapeutique pour maladies chroniques, Département de médecine communautaire, de premier recours et des urgencies, Hôpitaux Universitaires de Genève, Geneva, Switzerland; ${ }^{e}$ GP Winyates Health Centre, Fellow National Institute for Health and Care Excellence, Winyates, UK; ${ }^{f}$ Department of Internal Medicine, Medical University of Graz, Graz, Austria; 9Vice President of European Union of General Practitioners (UEMO), Lausanne, Switzerland; h Division of Endocrinology, Metabolism and Diabetes, Department of Medicine, Istanbul University, Cerrahpasa Medical Faculty, Istanbul, Turkey; iDepartment of Integrative Physiology, Faculty of Medicine, University of Fribourg, Fribourg, Switzerland
\end{abstract}

\section{Keywords}

Obesity · Overweight · Primary care · GPs · Management · Behavioural therapy · Motivational interviewing · Conservative treatment $\cdot$ Bariatric/metabolic surgery

\section{Abstract}

The first contact for patients with obesity for any medical treatment or other issues is generally with General Practitioners (GPs). Therefore, given the complexity of the disease, continuing GPs' education on obesity management is essential. This article aims to provide obesity management guidelines specifically tailored to GPs, favouring a practical patient-centred approach. The focus is on GP communication and motivational interviewing as well as on therapeutic patient education. The new guidelines highlight the importance of avoiding stigmatization, something frequently seen in different health care settings. In addition, managing the psychological aspects of the disease, such as improving self-esteem, body image and quality 
of life must not be neglected. Finally, the report considers that achieving maximum weight loss in the shortest possible time is not the key to successful treatment. It suggests that $5-10 \%$ weight loss is sufficient to obtain substantial health benefits from decreasing comorbidities. Reducing waist circumference should be considered even more important than weight loss per se, as it is linked to a decrease in visceral fat and associated cardiometabolic risks. Finally, preventing weight regain is the cornerstone of lifelong treatment, for any weight loss techniques used (behavioural or pharmaceutical treatments or bariatric surgery).

(C) 2019 The Author(s)

Published by S. Karger AG, Basel

\section{Introduction}

Obesity is a major public health issue as it is associated with increasing health and societal costs. The prevalence of the disease is continuously rising worldwide, especially in low and middle-income countries [1]. Therefore, improving obesity management in primary care settings is essential to reduce comorbidities and associated costs as well as to increase patients' quality of life. Numerous international guidelines on adult obesity management have been published in Europe, the US and Australia [2-7]. National guidelines [8-10] have also been produced taking into account the disparity, specificity and cultural differences of each country. Nevertheless, $100 \%$ global standardization and harmonization of obesity treatment remains elusive. One issue is that the guidelines are used by different medical specialists and public health professionals. The latter focus on obesity treatment for a whole nation (or a large group), whereas other medical disciplines (such as endocrinologists and obstetricians) require guidelines for treating heterogeneous individuals suffering from obesity. This means that guidelines should be tailored to the objectives of the health care professionals who use them.

Among the medical profession, General Practitioners (GPs) are at the frontline of treatment and screening in a primary care setting, as they are the first point of contact for adults with obesity. How the doctor communicates with patients is crucial to establish a good therapeutic alliance. In this way, GPs play a central role in obesity management, even though they are aware that obesity is also a societal problem which requires political decisions to be made on food regulation as well as changes to the built environment.

The purpose of this article is to develop concise, practical, patient-centred and well-illustrated guidelines for GPs, using evidence-based experimental and clinical studies, focusing in particular on high-quality evidence, i.e. grade A classification which constitutes a strong recommendation based on evidence from randomized controlled trials or meta-analysis of randomized controlled trials.

Since these guidelines are specifically tailored to GPs, we also consider "practice based" notions which are useful in primary care, as not all obesity treatments used have been subject to experimental studies. For clarity, the guidelines are often set out as numbered lists or bullet points.

These guidelines can be easily transferred into daily practice. They are based on topics which are often neglected: communicating with patients suffering from obesity and motivating them to change, patient therapeutic education, and avoiding stigmatization. An overall synopsis of the obesity management process, as developed in this paper, is presented in Figure 1. Different approaches for managing obesity, including weight loss drugs and bariatric surgery, are based on good communication with patients, motivation, objective clinical evaluation and behavioural therapy. The critical factors relevant for GPs in these areas are summarized in Table 1. 
Fig. 1. Overall synopsis of obesity management. Focus in this article is placed on communication with GPs and education of the patient.

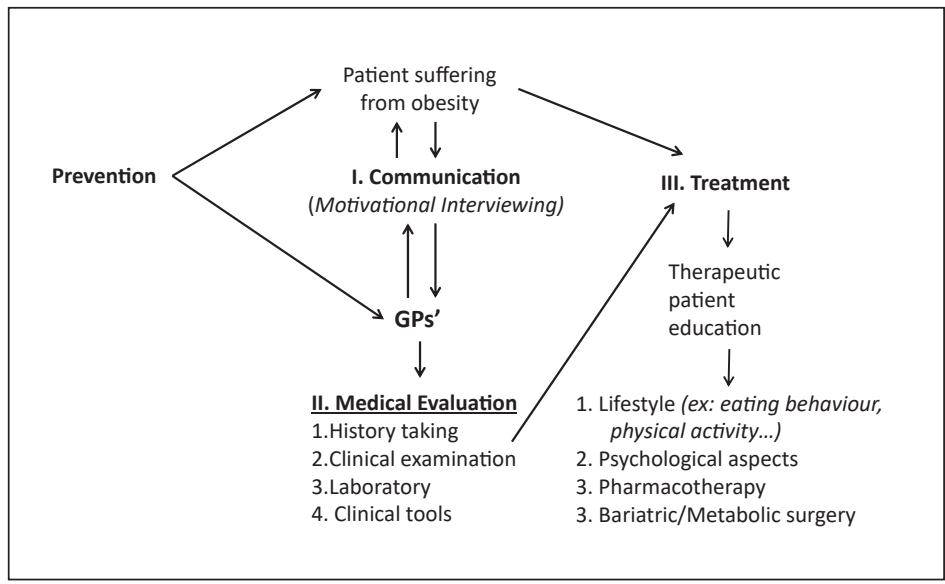

Table 1. The rationale for the approaches used in obesity management

\begin{tabular}{|c|c|}
\hline Approaches/measurements used & Rationale/explanations \\
\hline $\begin{array}{l}\text { Improve communication and } \\
\text { motivation }\end{array}$ & $\begin{array}{l}\text { Motivation is essential for adherence to treatment; readiness to } \\
\text { change will be evaluated over the long term using motivational } \\
\text { interviewing (MI) }\end{array}$ \\
\hline $\begin{array}{l}\text { Avoid stigmatization in a health } \\
\text { care setting }\end{array}$ & $\begin{array}{l}\text { Stigmatization is very frequent in healthcare settings; the } \\
\text { consequences are an increase in eating disorders, which worsen the } \\
\text { degree of obesity, as well as an increase in depression, suicidal } \\
\text { thoughts or even, in the worst cases, suicide; stigmatization can } \\
\text { decrease using MI }\end{array}$ \\
\hline Measure waist circumference & $\begin{array}{l}\text { It is a good indicator of visceral fat and a useful predictor of } \\
\text { cardiometabolic diseases; it can be measured at regular intervals to } \\
\text { monitor the decrease of visceral fat }\end{array}$ \\
\hline Treat comorbidities & $\begin{array}{l}\text { Comorbidities should be treated as a priority, mainly the } \\
\text { cardiometabolic diseases, to decrease mortality }\end{array}$ \\
\hline Use a multidisciplinary team & $\begin{array}{l}\text { A multidisciplinary team (obesity medical specialist, dietician or } \\
\text { nutritionist, specialist in physical activity, psychiatric or } \\
\text { psychologist, nurse and patient's GP) is more efficient; this team will } \\
\text { work in a network system }\end{array}$ \\
\hline Assess weight loss & $\begin{array}{l}5-10 \% \text { weight loss from initial weight is already sufficient to } \\
\text { decrease comorbidities }\end{array}$ \\
\hline $\begin{array}{l}\text { Consider lifestyle behaviour } \\
\text { change }\end{array}$ & $\begin{array}{l}\text { Behavioural modifications can induce } 5-15 \% \text { weight loss; it will also } \\
\text { help to improve body image, self-esteem, self-affirmation and quality } \\
\text { of life }\end{array}$ \\
\hline Increase physical activity & $\begin{array}{l}\text { Fit patients with obesity have a lower mortality risk, all aetiologies } \\
\text { included, than normal weight sedentary patients. Moreover, regular } \\
\text { physical activity decreases weight regain and the risk of weight } \\
\text { cycling after weight loss }\end{array}$ \\
\hline Avoid weight cycling & $\begin{array}{l}\text { After weight loss, particular attention will be given to avoiding } \\
\text { weight regain and weight cycling; patients can weigh themselves } \\
\text { approximately every } 2 \text { weeks; if the patient gains 3-4 kg quickly, he/ } \\
\text { she should not wait too long before visiting the GP to be assessed }\end{array}$ \\
\hline
\end{tabular}


Table 2. Potential consequences of stigmatization in patients with obesity

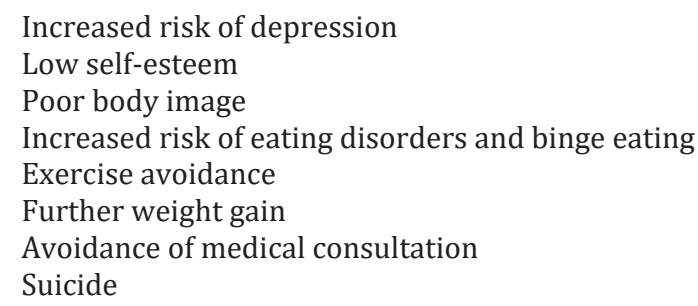

\section{Communication in Adult Obesity Management}

\section{Avoid Stigmatization}

As shown in Figure 1, communication is a fundamental aspect of obesity treatment. We must acknowledge that the discrimination and stigmatization of patients with obesity is surprisingly common in health care settings [8,12-15]. This includes among GPs, obesity specialists, psychiatrists, psychologists, obstetricians, dieticians and nurses. In fact, many studies $[13,14]$ have reported that stigmatization frequently occurs in different settings, at workplaces, in public, in the media, among family and friends and in places where it is least expected, namely among GPs, paediatricians, and obesity experts. A number of GPs and obesity specialists think that patients with obesity are lazy, non-compliant, weak-willed, unintelligent, lacking will-power and even dishonest. Many patients feel their GP is dismissive of them, and so avoid further consultation and treatment [12-14]. Therefore, it is particularly important to welcome the patient to the medical practice and to improve GPs' attitudes.

The consequences of stigmatization are deleterious: an increase in eating disorders, a decrease in physical activity, both leading to additional weight gain and greater obesity, as well as an increase in depression, suicidal thoughts or even, in the worst cases, suicide [1214]. These consequences are summarized in Table 2.

Given the frequently observed negative attitudes of some health professionals compromising the treatment's efficacy, how can the management of patients with obesity be improved? Globally, patient management can be ameliorated by decreasing negative attitudes by taking these actions $[8,13,14]$ :

1 Welcoming the patient to the practice with empathy and without any negative judgements or bias.

2 Understanding that a patient with obesity has already chronically been exposed to negative experiences with health professionals related to his/her excess body weight.

3 Recognizing that obesity has a complex aetiology - it is a multifactorial disease caused by both individual and external factors - and that this condition is not fully under voluntary control.

4 Taking care to not use inappropriate or hurtful words in order to maintain a positive, constructive and helpful relationship with the patient.

5 Asking the patient whether he/she is willing to speak about his/her body weight before introducing the discussion around obesity, especially if the patient did not come to the GP for this specific issue.

6 Semantically, it is important to talk about a patient "with obesity" rather than an "obese" patient; this will be considered less stigmatizing by the patient.

In practice, GPs may not have been specifically trained in patients communication skills, in particular with those suffering from obesity. So, in practical terms, what questions could health professionals ask themselves before managing obesity [8, 12-14]? Five key questions are relevant: 
1 What are the key messages that I would like to transmit to the patient with obesity?

2 Will these messages empower a motivation to change his/her lifestyle?

3 Does the (excess) body weight of a person per se engender bias and prejudice about his/ her character, intelligence, professional success, lifestyle and capacity to be happy or efficient in daily life?

4 How do I answer the individual needs of the patient with obesity?

5 Am I listening carefully to him/her and am I aware of his/her concerns and needs? In daily practice, the following messages and tools can be used while communicating with the patient:

- In terms of communication technique, Motivational Interviewing (MI) helps the patient to change (see below).

- Some inadequate terminology and expressions used to communicate with patients suffering from obesity (hurtful, judgmental, and critical language) could be devastating and could compromise further treatments.

- Many patients have already attempted to lose weight repeatedly in the last decade or more.

- Explore all causes of medical problems; do not focus only on weight per se.

- Help the patient to select modest and realistic goals (step by step), remembering that even a modest weight loss (5-10\% of initial weight) can have a beneficial effect on comorbidities (i.e. cardiometabolic risks) [2-10].

- Focus on positive behavioural changes rather than on the pressure or "the obligation" to lose weight. For example, suggest changes such as eating more fruit and vegetables and increasing physical activity rather than focusing on the weight change itself $[6,8]$.

- Decreasing waist circumference may be even more important than weight loss per se [6-8].

- Self-esteem, self-affirmation, body image and well-being are essential issues [6-8].

\section{Motivational Interviewing (MI)}

Motivation is one of the key measures of the success of obesity management (i.e. adherence to treatment). Motivation is essential if behaviour change is to be sustained over the long term. MI is a very efficient communication technique, a non-judgemental, collaborative discussion style allowing reinforcement of the patient's own motivation and stimulating his or her involvement towards a behavioural change [16-18].

How do I communicate adequately with the patient, with empathy and sensitivity using MI?

- The aim is to develop a pleasant and warm atmosphere based on mutual trust so that the patient feels relax and comfortable, as well as building a strong therapeutic alliance.

- The tone of MI is fully empathic and encouraging without any prejudice or bias.

- The patient with obesity is considered to be his/her own "expert" and each patient selects, with the help of the GPs, the pertinent changes in the specific area which he/ she would like to initiate behavioural change. A real partnership is built with the GP (see below).

- When confronted with any potential change, ambivalence is a natural expected phenomenon. The physician can help the patient to resolve his/her ambivalence towards behavioural change through reflective listening and open-ended questions. The physician will explore the decisional balance, asking first for the negative aspects of the potential change, following by the positive ones; the latter should be more numerous than the former. The priority is to resolve ambivalence before progressively moving on to the subsequent changes. The discussion focuses on goals and values and elicits change talk. 
Durrer Schutz et al.: Management of Obesity by GPS

Table 3. Useful questions to ask to the patient for increasing motivation to change

May we talk about your weight?

How are you feeling about your weight at this time?

How important is it for you to change your behaviour now?

How confident are you that you can make a change in your lifestyle?

Are there any stressful events in your life at the moment that could be a barrier to change?

If you decide to change your lifestyle, what would you change?

What would be the two or three advantages that you could get out of it?

If you decide to make this change, how would you do it?

How did our discussion help you to go forward? How do you see the follow-up?

What does "healthy eating" mean to you?

Do you feel the sensations of hunger and satiety?

Do you eat when you are bored, stressed or sad?

When would be the best time of day (or evening) to be physically active?

What does physical activity mean to you?

What kind of physical activity do you enjoy now or did you enjoy in the past?

What are some reasonable goals you could set regarding your weight?

What kind of changes would you be willing to start with?

What kind of help would you like to meet your goals?

There are 3 keys to potential success:

1 The perceived importance of change must be high.

2 The patient feels confident in his/her ability to change behaviour.

3 This change is a priority for the patient. It's the right moment to do it.

Another important issue is how to raise the overweight/obesity topic in a consultation. A number of studies indicate that patients with obesity prefer the terms "weight" or "BMI" when talking about obesity and dislike the terms "fatness", "excess fat" and "obesity".

It seems appropriate to give examples of practical generic questions which can be asked by GPs in general practice (Table 3). These questions can trigger and help to increase motivation to change [16-20].

\section{Clinical Evaluation of Adults with Obesity}

Guidelines for the appropriate clinical evaluation of the obese adult patient have been included in the recent European Guidelines for Obesity Management in Adults published in 2015 [2] as well as in the Swiss Consensus of Obesity released in 2016 [8]. The clinical evaluation includes the patient's history of obesity, the physical examination, assessment of lifestyle habits, psychological status, and the laboratory assessment.

\section{Anamnesis}

History taking from the patient with obesity can be summarized in 12 points or objectives [2-10]:

1 Patient representations, expectations and motivation to change.

2 Measurement of the patient's body weight over time (from birth to actual body weight) as well as exploring the genetic factors, exogenous stimuli and events which have led to weight gain or to significant variations of body weight (Fig. 2). In other words, determine if obesity dates back from childhood or if weight gain is recent, as this will lead to different management approaches. 


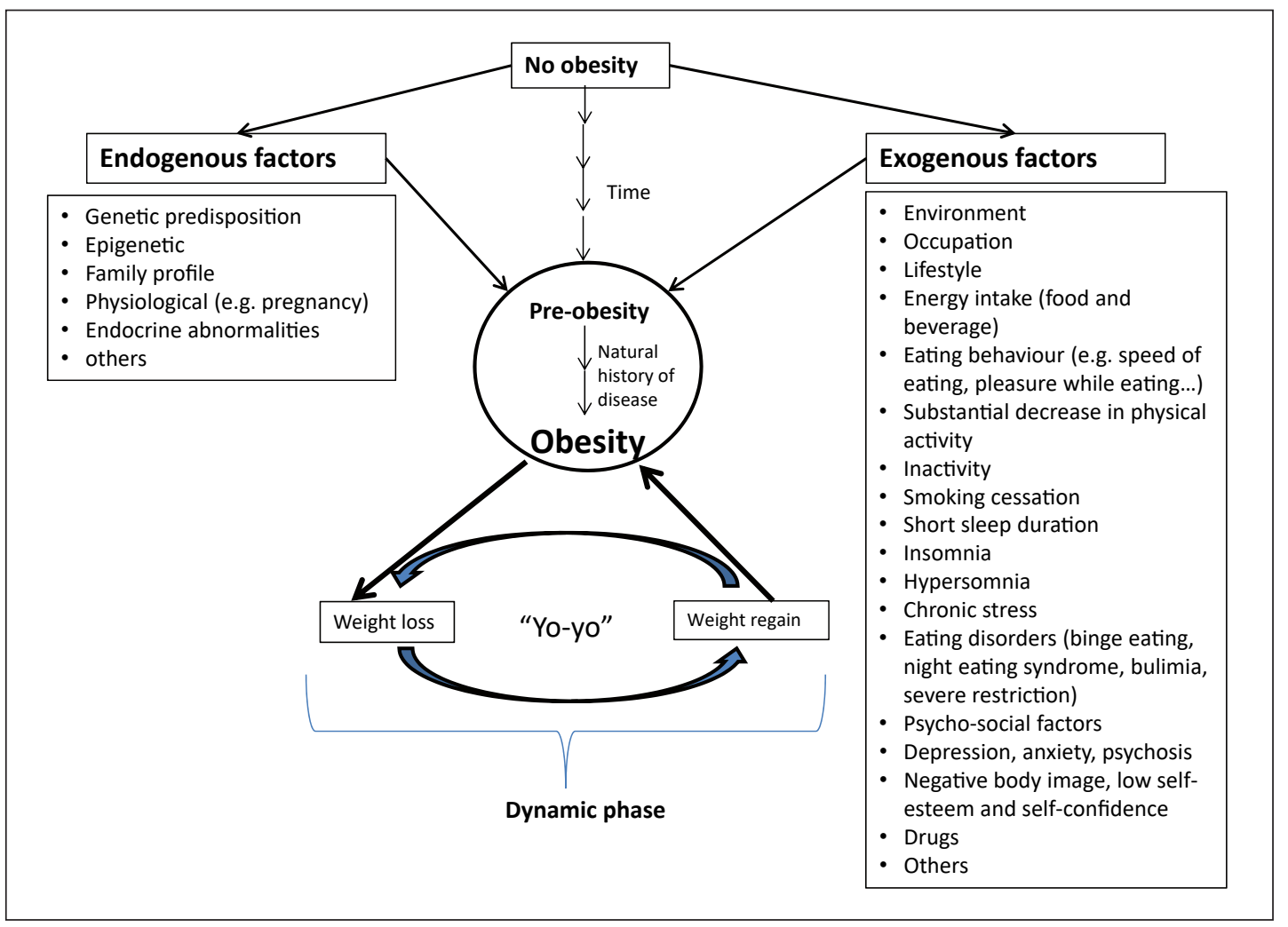

Fig. 2. History taking: schematic view of the major endogenous and exogenous aetiological factors. To identify and understand the natural history of obesity from the pre-obese state is part of the process. Note that weight loss per se is not considered the first priority of obesity treatment. Rather, managing comorbidities and preventing weight gain or regain after weight loss is the priority.

3 Identification of the reasons for gaining weight. Any dynamic variation in body weight over the patient's lifespan can be reported on a simple graph, and the aetiology of these variations should be determined: physiological aspects (pregnancy), drugs, pregnancy, decrease in physical activity, eating disorders, psychological problems, child neglect etc. An independent proxy of evolving body weight is changes in clothes sizes during adulthood. It is necessary to track which phase the patient is currently in: losing or gaining weight (dynamic phase) or stabilized body weight (maintenance phase). In the former phase, body weight must be stabilized before initiating weight loss.

4 Evaluation of past treatments and their effects are important, such as the types of slimming diet, weight cycling (yoyo effect), failure and success as well as the attitude of family and friends (or diet saboteurs).

5 Degree of motivation for the treatment and its reasons.

6 Degree of expectancy in terms of weight loss and waist circumference and changes in their own life.

7 Definition of the professional and family lifestyle, in particular physical activity (organized sports, leisure time, physical activity, keeping active) as well as inactivity and sedentary behaviour. A switch from an active lifestyle or occupation to an inactive one constitutes a risk factor for weight gain. In addition, losing one's job, getting married (or divorced) or living through grief could be a trigger for weight gain.

8 Exploration of the family history of obesity and cardiometabolic diseases. 
Durrer Schutz et al.: Management of Obesity by GPS

Table 4. Adult BMI cut-off points in Caucasians

\begin{tabular}{lc}
\hline Weight status & $\mathrm{BMI}, \mathrm{kg} / \mathrm{m}^{2}$ \\
\hline Underweight & $<18.5$ \\
Normal range & $18.5-24.9$ \\
Overweight & $25.0-29.9$ \\
Obesity & $\geq 30$ \\
$\quad$ Obesity class I & $30.0-34.9$ \\
Obesity class II & $35.0-39.9$ \\
Obesity class III & $\geq 40$ \\
\hline
\end{tabular}

9 Assessment of the psychological impact of negative body image on the patient and his/ her self-esteem, investigating the desired body weight or image, the speed of weight loss desired and, above all, the motivation to change lifestyle. An unrealistic objective of weight loss or of slimming speed (e.g. 5-10 kg in 10-14 days) is a negative prognosis.

10 Assessment of eating disorders, depression, anxiety, stress, poor sleep quality, psychological profile and social aspects (family contact).

11 Exploration of food intake and behavioural profile: "What and how do you eat? With whom do you eat? Where do you eat?" Location of the meal, at home or elsewhere, at the table, watching television, using a smartphone or tablet or listening to the radio. Structure, duration, timing and composition of the meals, portion size and number of plates eaten per meal, nutritional "errors", consumption of sugar-sweetened drinks or alcohol.

12 Important question for the patient: "Do you eat mindfully?" Evaluation of the physiological sensations of hunger and satiety, speed of eating, pleasure while eating. Occurrence of snacking, binge eating, hyperphagia, bulimia, night eating syndrome etc.

Figure 2 presents a schematic overview of the major aetiological factors (divided into endogenous vs. exogenous), which can be tracked by history taking (anamnesis).

\section{Physical Examination}

It should be firstly remembered that the patient with obesity requires certain adapted tools, behaviours and skills for physical examination. The clinical evaluation includes the following measurements [2-10]:

\section{Body Weight}

Body weight is assessed in the lightest clothing practicable and with empty pockets, to avoid any feeling of embarrassment. Weight assessment should be in a discrete room, out of sight of external people and after getting the patient's agreement. Weight is measured using an appropriate (calibrated) scale ranging up to $200 \mathrm{~kg}$ (450 pounds). Height is measured without shoes.

From the two above variables, BMI $\left(\mathrm{kg} / \mathrm{m}^{2}\right)$ is calculated. For children under 18 years of age, ensure that age/sex-appropriate BMI centile reference ranges are used when interpreting BMI.

Obesity is classically defined as a BMI $>30 \mathrm{~kg} / \mathrm{m}^{2}[2-10,20,21]$ (Table 4). This cut-off value is not valid for children and adolescents (age and gender-dependent cut-offs) as well as for certain non-Caucasian ethnicities (e.g. Asians), in which the cut-off point needs to be lowered by 2.5 units. In the elderly, the cut-off values for BMI classification should be used cautiously for at least two reasons: first, there is a "natural" progressive body weight gain from 20 to 65 years of age in industrialized countries, which contributes to moderating the fat-free mass loss with age, and second, from 65 to 70 years of age or above, an overweight patient has a lower mortality rate than a skinny one [22]. 
Fig. 3. The measurement of abdominal circumference with a non-stretchable tape is not as easy as it looks on the schematic silhouette. It has a relatively poor inter-investigator accuracy, particularly in obese individuals. Alternative objective circumference assessment without skin contact (e.g. by a laser beam) is currently available but the instrument is too costly for GPs' routine medical practice [66].

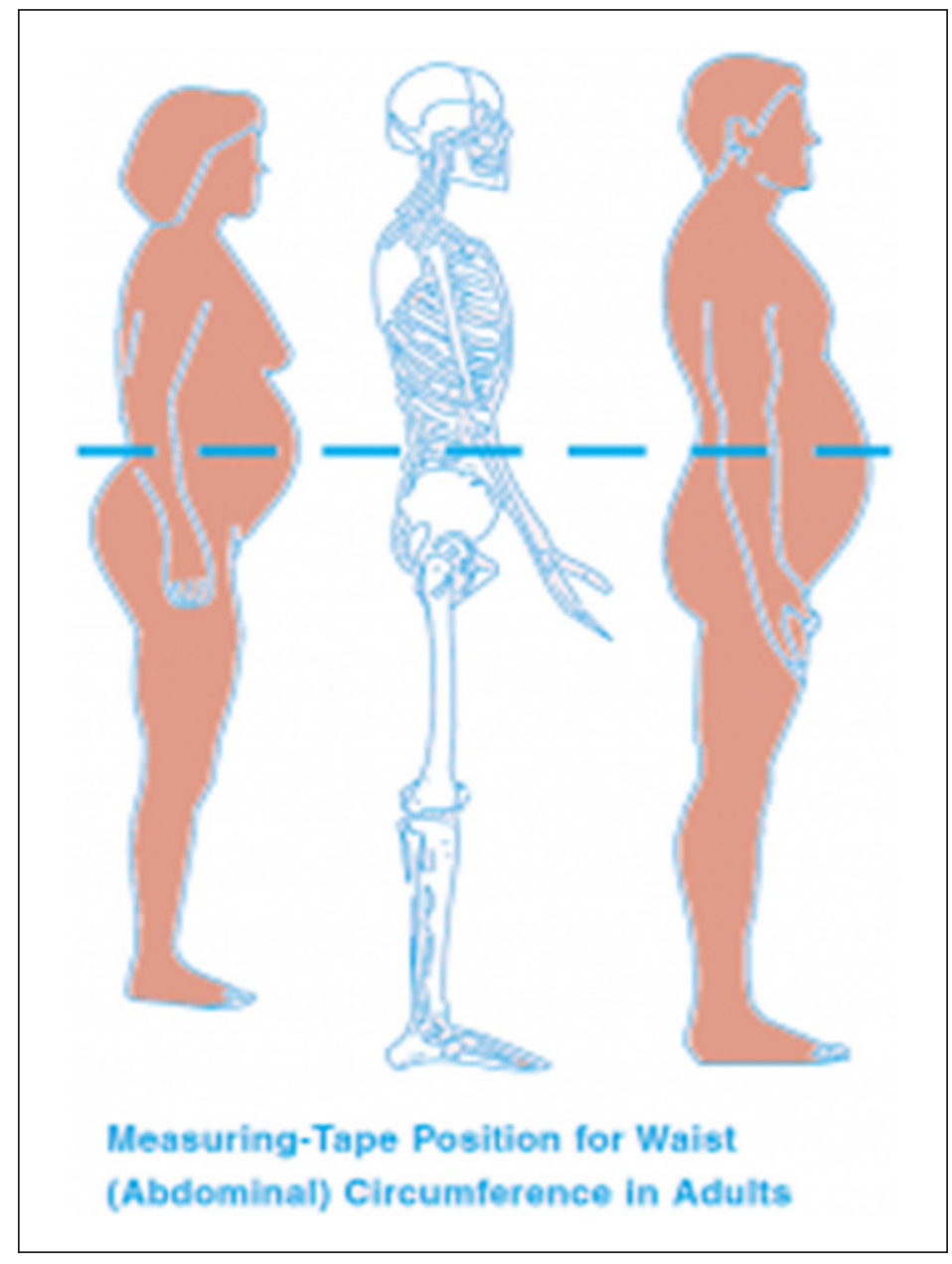

The use of body composition measurements for assessing both fat mass and fat-free mass is recommended for research purposes, but these techniques are not strictly required in clinical practice (high cost, variable accuracy).

\section{Waist Circumference}

Waist circumference is a reasonably good indicator of abdominal fat and a useful predictor of cardiometabolic diseases [3, 8,21-24]. Waist measurement is taken over light clothing in order to avoid embarrassment. Waist circumference is measured at the end of a normal expiration in the horizontal plane midway between the superior iliac crest and the lower margin of the last rib [2], using a measuring tape placed horizontally around the abdomen and without compressing the skin (Fig. 3).

Waist circumference is considered a reasonably good proxy for the quantity of visceral fat and can be used to evaluate the cardiometabolic risks related to body fat distribution. When the BMI of the patient is above $35 \mathrm{~kg} / \mathrm{m}^{2}$, the importance of this measurement is less obvious, unless the two measurements are combined in a predictive model.

"Normal" waist circumference references (relatively strict values, even for certain nonobese and elderly individuals) are $<80 \mathrm{~cm}$ for women and $<94 \mathrm{~cm}$ for men. Cut-off points indicating higher cardiometabolic risks are $>88 \mathrm{~cm}$ for women and $>102 \mathrm{~cm}$ for men. Note that a gynoid morphotype (low waist/hip ratio: female $<0.8$; male $<0.9$ ) constitutes a protective profile against cardiometabolic risks [23, 24]. 


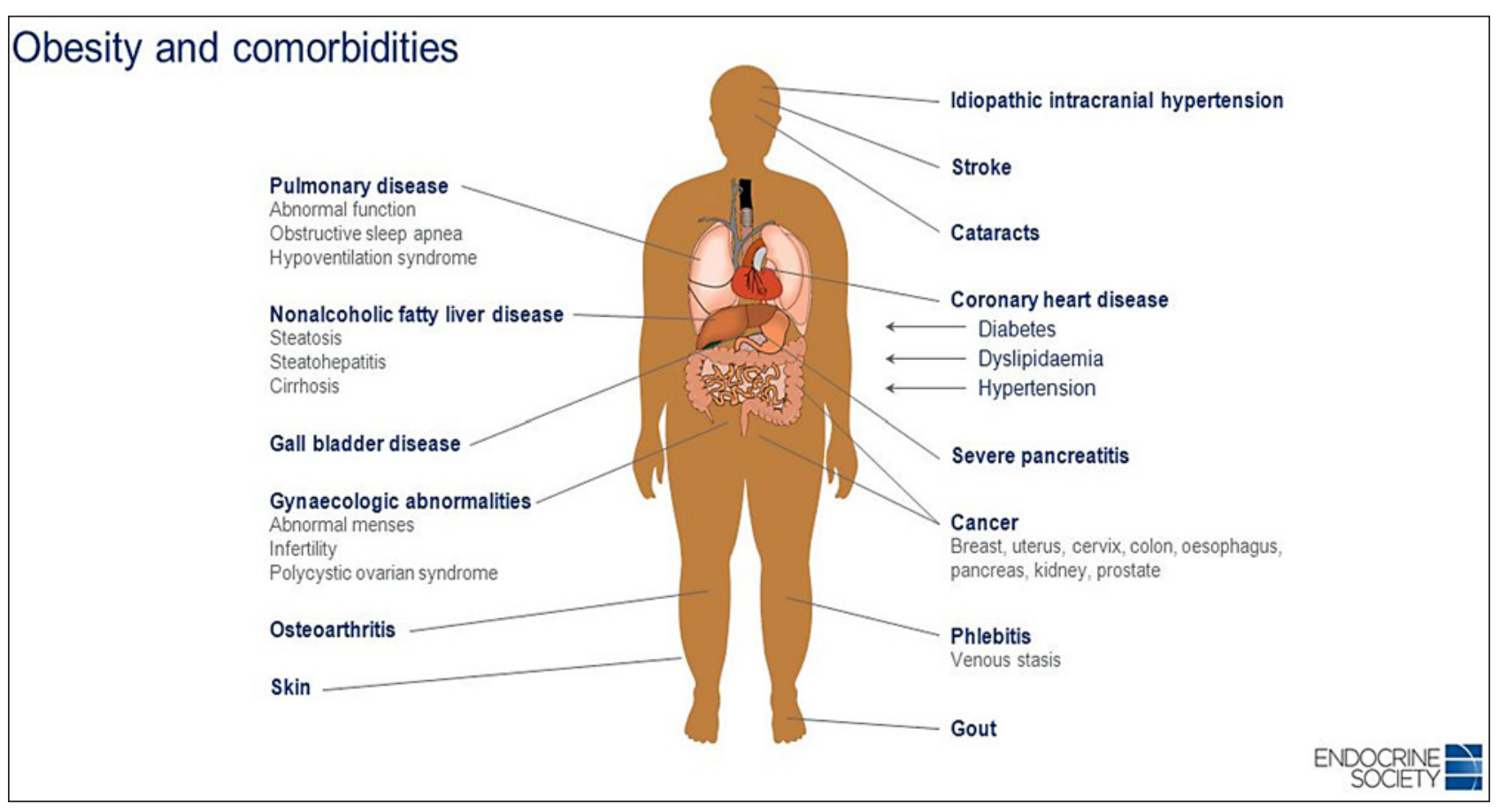

Fig. 4. Obesity and its multiple comorbidities affecting many systems, organs and tissues (source: Jeffrey Newman).

\section{Blood Pressure}

Blood pressure is measured after about 10 min of rest in a sitting position (in the waiting room or elsewhere). Assessment of blood pressure is done using a cuff size (XXL) adapted to the circumference of the patient's upper arm. Longitudinal home monitoring of blood pressure by the patient (using an accurate and precise sphingomanometer) could add valuable information for GPs, which may reduce the well-known "white coat" effect.

\section{Comorbidities Status}

Enquiry for comorbidities. The sequence is to explore clinical symptoms and signs of the main comorbidities by making a complete medical status (diabetes type 2, hypertension, cardiovascular disease, asthma, sleep apnoea syndrome, gallbladder disease, NASH (nonalcoholic steatohepatitis), osteoarthritis, colorectal cancer, kidney cancer, breast cancer etc). Identify "metabolically healthy" obesity, especially when the patient has a high cardiorespiratory fitness [25]. Look for acanthosis nigricans (brown colouration of the skin on the neck or in the armpits) related to insulin resistance $[26,27]$. The different comorbidities associated with obesity are shown in Figure 4.

Metabolic Syndrome

Patients who present a metabolic syndrome are prone to develop cardiometabolic disease and especially type 2 diabetes [28].

Five criteria for metabolic syndrome (International Diabetes Federation definition, https://www.idf.org/e-library/consensus-statements/60-idfconsensus-worldwide-definitionof-the-metabolic-syndrome.html) have been defined as follows (no. 1 plus other 2 criteria have to be fulfilled for diagnosis of metabolic syndrome):

1 Waist circumference $>94 \mathrm{~cm}$ in men and $>80 \mathrm{~cm}$ in women 
2 Triglycerides levels $\geq 1.7 \mathrm{mmol} / \mathrm{L}$ or specific treatment for this lipid abnormality

3 HDL cholesterol $<1.03 \mathrm{mmol} / \mathrm{L}$ in males and $<1.29 \mathrm{mmol} / \mathrm{L}$ in females

4. Systolic blood pressure: systolic $\geq 130$ or diastolic $\geq 85 \mathrm{~mm} \mathrm{Hg}$ or treatment of previously diagnosed hypertension

5 Glucose levels $\geq 5.6 \mathrm{mmol} / \mathrm{L}$ or previously diagnosed type 2 diabetes.

\section{Laboratory Assessment}

Laboratory assessment constitutes a valuable part of the evaluation of the patient at baseline and should be based on clinical evaluation. It is an objective measurement which complements history taking and clinical evaluation [2-10].

A summary of the appropriate laboratory assessment used in obesity management is given below. The maximum laboratory evaluation includes 10 assessments, but in practice fewer measurements may be necessary. The first 4 are the most important.

1 Fasting blood glucose

2 Lipid profile (total cholesterol, HDL-cholesterol, LDL-cholesterol, triglycerides)

3 Liver function (GOT, GPT, Gamma GT), with liver investigation (ultrasound, biopsy), if elevated liver enzymes

4 Kidney function (creatinine)

5 Index of inflammation (Hs-CRP, ferritin)

6 Uric acid in blood, if gout

7 Thyroid function (TSH)

8 Cardiovascular assessment (ergometry, echocardiography), if indicated

9 Sleep apnoea investigation, if indicated

10 Endocrine investigations (Cushing, hypothalamic disease), if clinically indicated.

\section{Obesity Treatment}

\section{Treatment Goals}

The principal goals in obesity management are to prevent complications by trying to keep the patient metabolically healthy (if possible), to prevent or to treat comorbidities if they are already present, to fight against stigmatization and to restore well-being, positive body image and self-esteem. Body weight loss per se is not considered the first priority. Motivation to change is supported over the long term [2-10].

The treatment goals will be obviously tailored to the complications. Table 5 (adapted from [3]) summarizes the actions to be taken. The predictive weight loss is also given as an indicator of what could be achieved to decrease cardiometabolic risks. These range from 5 to $15 \%$ of expected weight loss depending on the pathology. It is known that this amount of weight loss to be achieved, at least in the medium term, is possible with behavioural treatment.

\section{Comprehensive Adult Obesity Management in General Practice [2-10]}

GPs are aware that a patient with obesity entering the medical practice may not be coming for this issue but for other medical problems. A simple algorithm is proposed to clarify, step by step, the possible actions to be taken for comprehensive obesity management in adulthood (Fig. 5).

GPs are dealing with heterogeneous patients, with different backgrounds and levels of education. The medical jargon during the consultation can be a barrier to the patient's understanding of the disease. Educating the patient is, as a result, a very important phase of the 
Durrer Schutz et al.: Management of Obesity by GPs

Table 5. Treatment targets based on diagnosis in the medical management of patients with obesity (adapted from [3])

\begin{tabular}{lcl}
\hline Diagnosis & $\begin{array}{l}\text { Weight loss } \\
\text { target, } \%\end{array}$ & Expected outcome \\
\hline Metabolic syndrome & 10 & Prevention of type 2 diabetes \\
\hline Type 2 diabetes & $5-15$ & $\begin{array}{l}\text { Reduction in glycated haemoglobin; reduction in diabetes medi- } \\
\text { cation; diabetes remission if short duration }\end{array}$ \\
\hline Dyslipidaemia & $5-15$ & Lower triglycerides; increase HDL, decrease LDL \\
\hline Hypertension & $5-15$ & Lower blood pressure; decrease in medication \\
\hline NAFLD & 1040 & Reduction in intrahepatocellular lipids and inflammation \\
\hline Polycystic ovary syndrome & $5-15$ & $\begin{array}{l}\text { Ovulation; reduction of hirsutism; decrease in androgen levels; } \\
\text { increase insulin sensitivity }\end{array}$ \\
\hline Sleep apnoea & $7-11$ & \begin{tabular}{l} 
Decrease apnoea/hypopnoea index \\
\hline Asthma
\end{tabular} \\
\hline Gastro-oesophageal reflux disease & 10 or more & Reduced symptoms \\
\hline
\end{tabular}

Note that weight loss will depend upon the nature of comorbidity.

treatment. Patient education will improve the therapeutic efficiency and the patient's motivation to change in the long term $[29,30]$. It should enable patients to increase and keep abilities and skills which will help them to live with their disease. It is a permanent process included in lifelong treatment. In addition, it is patient-centred, involving awareness of how obesity leads to comorbidities and learning a process of self-management, psychological support and health behaviours. Patient education aims to help patients and their family to better understand obesity, to live healthier lives and to improve body image, self-esteem and quality of life, taking into account their beliefs and representation about their disease. One should address patients' subjective and objective needs and help them to become progressively self-supporting.

Considering the large inter-individual variability of patients with obesity, each with their own beliefs, family history and positive or negative attitudes towards a proposed treatment, it is fundamental to let the patient choose the area they feel able to make behavioural changes. As shown in Figure 6, there are three complementary areas: nutrition, physical activity, eating behaviour and psychological aspects. An overview of the decisions to be taken according to the level of cardiometabolic risks estimated from BMI and waist circumference is shown in Table 6 (adapted from [2]). The initial level of intervention is discussed with the patient.

\section{Lifestyle and Behavioural Therapy}

\section{General Considerations [2-10, 31-35]}

The role of a GP is not to shame but to avoid stigmatization of patients with obesity by encouraging, motivating and supporting them in their choices in a real partnership with the patient.

Ideally, an interdisciplinary team made up of the patient's GP, an obesity medical specialist, a dietician or nutritionist, a specialist in physical activity, a psychologist or psychi- 


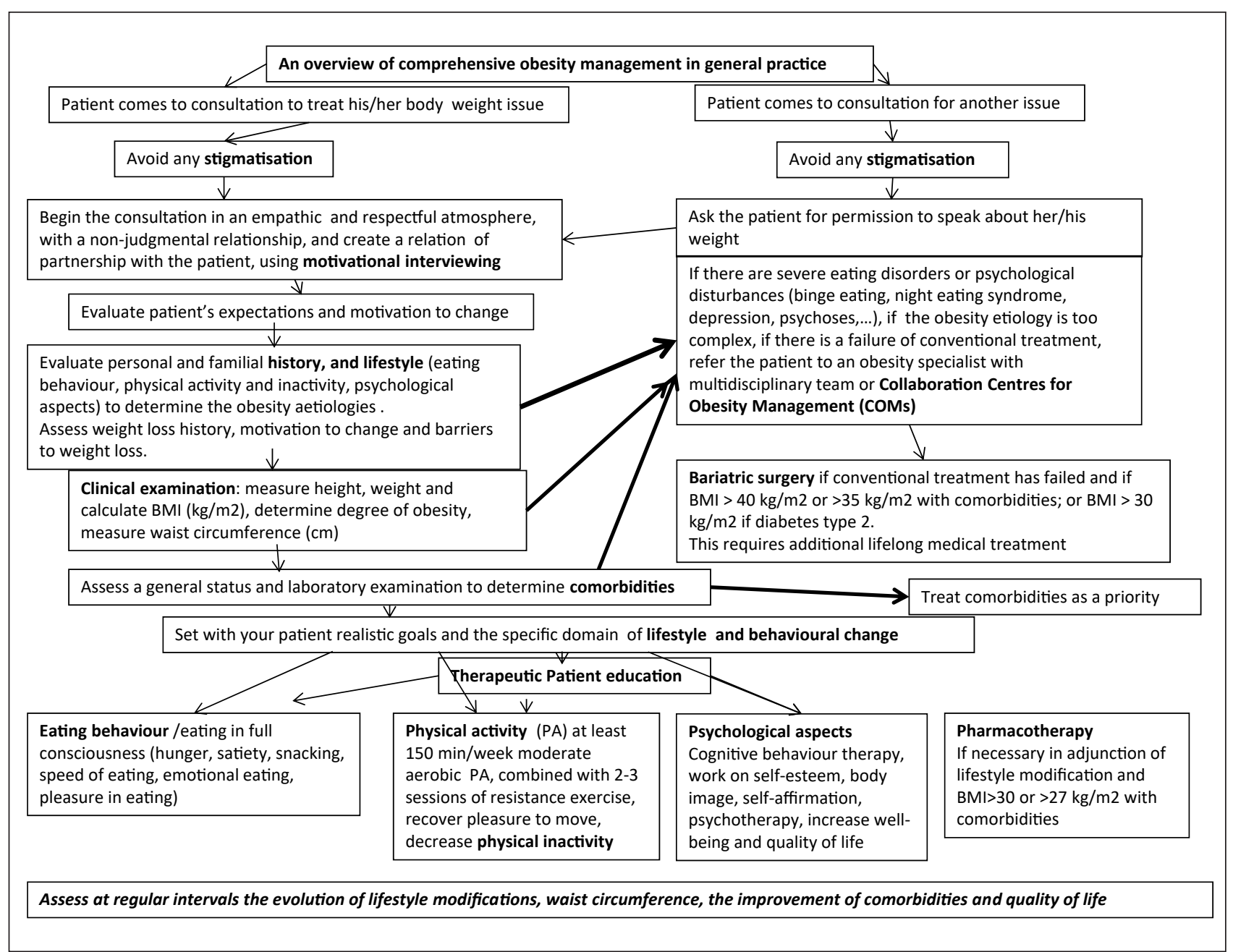

Fig. 5. Overview of a comprehensive step-by-step management of obesity in medical practice. The decision algorithm is obviously a simplification of the reality and shows the vast number of factors to be considered for optimizing the individual management with its four non-dogmatic non-competitive treatments options.

Table 6. A guide to deciding the initial level of intervention to discuss with the patient (adapted from [2])

\begin{tabular}{llll}
\hline BMI, $\mathrm{kg} / \mathrm{m}^{2}$ & \multicolumn{2}{l}{ Waist circumference, $\mathrm{cm}$} & Comorbidities \\
\cline { 2 - 3 } & $\begin{array}{l}\text { men }<94 \mathrm{~cm} / \\
\text { women }<80 \mathrm{~cm}\end{array}$ & $\begin{array}{l}\text { men } \geq 94 \mathrm{~cm} / \\
\text { women } \geq 80 \mathrm{~cm}\end{array}$ \\
\hline $25.0-29.9$ & $\mathrm{~L}$ & $\mathrm{~L}$ & $\mathrm{~L} \pm \mathrm{D}$ \\
$30.0-34.9$ & $\mathrm{~L}$ & $\mathrm{~L} \pm \mathrm{D}$ & $\mathrm{L} \pm \mathrm{D} \pm \mathrm{S}^{*}$ \\
$35.0-39.9$ & $\mathrm{~L} \pm \mathrm{D}$ & $\mathrm{L} \pm \mathrm{D}$ & $\mathrm{L} \pm \mathrm{D} \pm \mathrm{S}$ \\
$\geq 40$ & $\mathrm{~L} \pm \mathrm{D} \pm \mathrm{S}$ & $\mathrm{L} \pm \mathrm{D} \pm \mathrm{S}$ & $\mathrm{L} \pm \mathrm{D} \pm \mathrm{S}$
\end{tabular}

L, lifestyle intervention (diet and physical activity); D, consider drugs; $\mathrm{S}$, consider surgery. * Patients with type 2 diabetes on individual basis. 


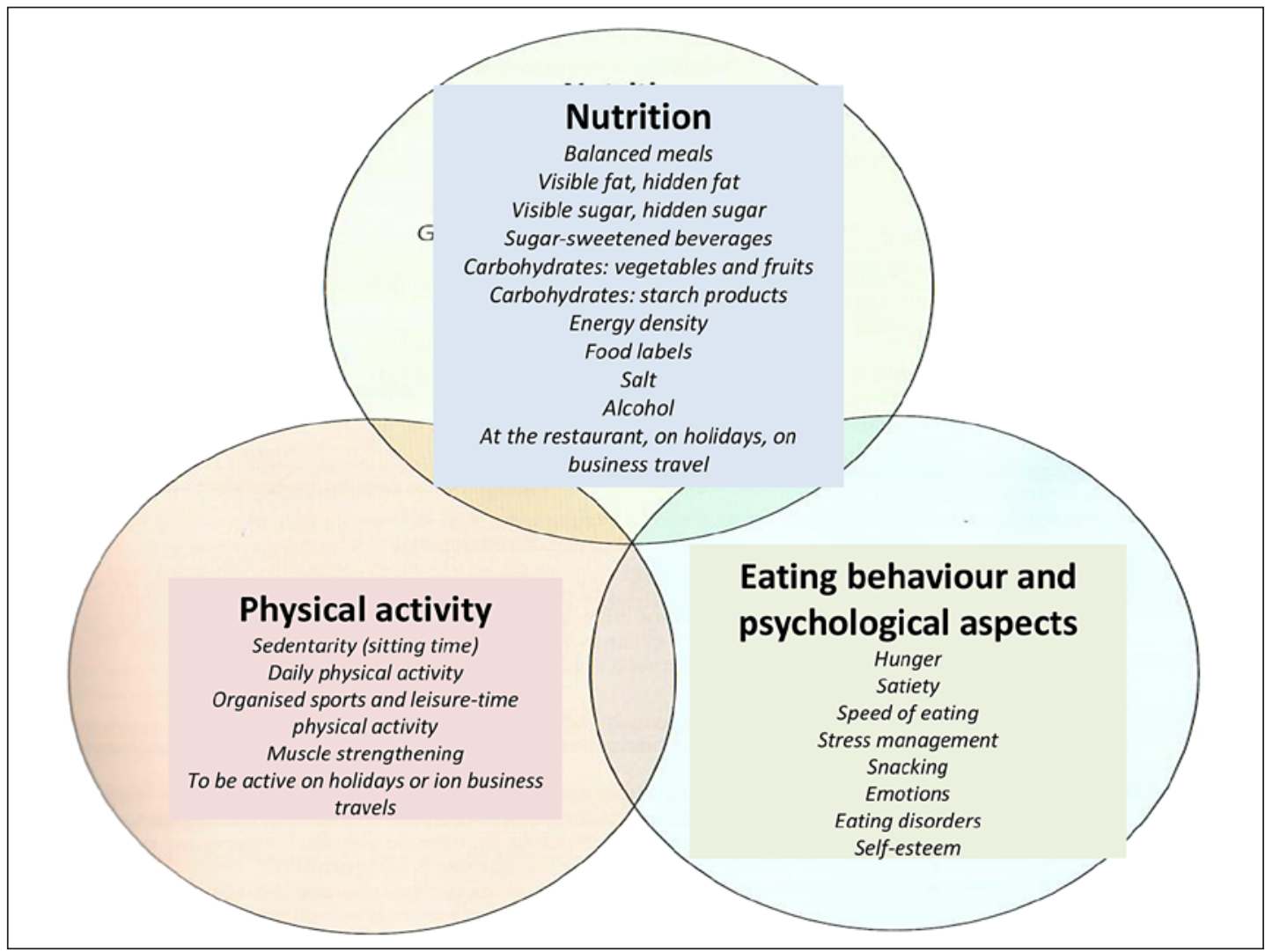

Fig. 6. How to communicate with the patient with obesity? The GP presents this scheme to the patient during the consultation in order to help him/her choose which area they would like to initiate behavioural modification.

atrist and a nurse will look after the patient. This team should work in a network system. Patients may benefit from joining a self-help group if possible.

The goals, in terms of weight loss and speed of slimming, must be achievable and progressive (5-10\% of initial weight). The goal will focus more on lifestyle changes, body composition and decreasing waist circumference than on weight loss per se.

The patient is considered his/her own expert and chooses the area for behaviour modification with the support of his/her GP or obesity expert (Fig. 6).

The degree of motivation can be enhanced by using MI.

Patient education is relevant to help patients learn about their health. The use of therapeutic patient education clearly shows an improvement in health outcomes including quality of life. The approach includes nutrition, eating behaviour, physical activity and inactivity, stimulus control, systematic approaches for problem solving, stress reduction, cognitive behavioural therapy, psychological counselling or therapy, treatment of eating disorders, anxiety and depression as well as mobilization of social support structures through patient education $[29,30]$. It will also help to improve body image, self-esteem, self-affirmation and quality of life.

The different areas in which the patient finds a way to optimize his/her motivation and adherence to the treatments is shown above (Fig. 6). It includes i) nutrition and eating behaviour ii) physical activity and inactivity behaviours and iii) psychological aspects such as stress management. 
Table 7. General nutritional and behavioural advice given to the patient with obesity

1 Decrease energy density of food; increase vegetables and eat two portions of fruit per day; decrease fatty foods, especially saturated fat; decrease refined carbohydrates, sugar and sweetened beverages; decrease portion size, use a smaller plate and eat only one portion per meal

2 Avoid snacking and skipping meals (breakfast, for example: if you are not hungry early in the morning, you can eat your breakfast later, when you will feel hungrier)

3 Eat only in response to your sensation of hunger and stop when you feel a sensation of satiety; avoid eating if you are not hungry and avoid finishing your food if you feel full before the end of your meal

4 Eat slowly: a sensation of satiety will appear after about $20 \mathrm{~min}$ after the beginning of the meal

5 Eat mindfully

a Take a moment to relax, listen to your favourite music, and try to anticipate the meal to come

b Sit down at a table (no standing or walking) to eat without doing anything else (television, smartphone, tablet, radio, reading, etc.)

c Be aware of how the intensity of your hunger sensation decreases progressively throughout the meal

d Eat slowly and enjoy it, paying attention to the tastes, flavours, textures and temperature of the food; put down your knife and fork between bites

e Observe your emotions while eating

f Stop eating when you feel full and the pleasure of eating decreases

6 Keep a diary so you become aware of your eating behaviour (snacking, volume of meals etc.) and to identify the triggers for eating when you are not hungry (watching television, using a smartphone or tablet, walking past a bakery, feeling bored or frustrated etc.)

Nutrition and Eating Behaviour [8, 11, 31-37]

A number of patients with obesity no longer recognize the physiological sensations of hunger and satiety which control food intake. Therefore, they eat because it is time to eat, because they want to, for emotional compensation or as a reflex. The first step is therefore the most important: to recover the physiological sensations of hunger and satiety through practical exercises at home. This will determine food and energy intake and help to maintain metabolic equilibrium. It is essential to recognize the hunger sensation which reappears progressively 4-5 h after a "normal" meal - that of a "hole" in the stomach accompanied by noise. Waiting too long can be counterproductive because it could lead to a caloric overconsumption. It is important to eat quietly without perturbation or being involved in anything else (watching television, using a smartphone or tablet, listening to the radio, walking, reading a magazine etc.).

One approach is to eat slowly and mindfully [36], to smell the food before eating, to chew carefully, to keep it in the mouth to detect all the different textures, flavours and tastes; this will help to identify satiety. This sensation will appear about $20 \mathrm{~min}$ after the beginning of the meal and will contribute to the control of food intake. Step by step, the pleasure of eating will decrease until the end of the meal when full satiety occurs. The aim is to perceive the act of eating through all our senses, to recover the pleasure of eating and to avoid the perverted automatic behavioural reactions which lead to overeating. Practical tips for patients are presented in Table 7.

A schematic illustration (Fig. 7) provides a simplified approach for selecting appropriate food items on a normal size plate, considering that about one quarter of the area is covered by a source of protein (meat, poultry, fish, cheese, egg, lentils etc.) and the remaining part by starchy (non-sugar cereals) and other non-refined carbohydrate food as well as fruit and vegetables. The Mediterranean diet should be promoted. This diet has a high content of vegetables, fruits, legumes, complex starches and food rich in omega-3 fatty acid like fatty fish, 
Fig. 7. The plate ("normal" size) shows the typical balanced Mediterranean style diet, which is used as a model to show the proportion represented by each of the components: about half for vegetables, about one quarter for food rich in protein (meat, fish, cheese and legumes) and the last quarter for starchy food including cereals and grains. Fruits are shown on the periphery of the plate because they can be eaten between meals (apples, berries, etc.). (From: diet http://nutrition-sante.ch/ l-assiette-equilibree).

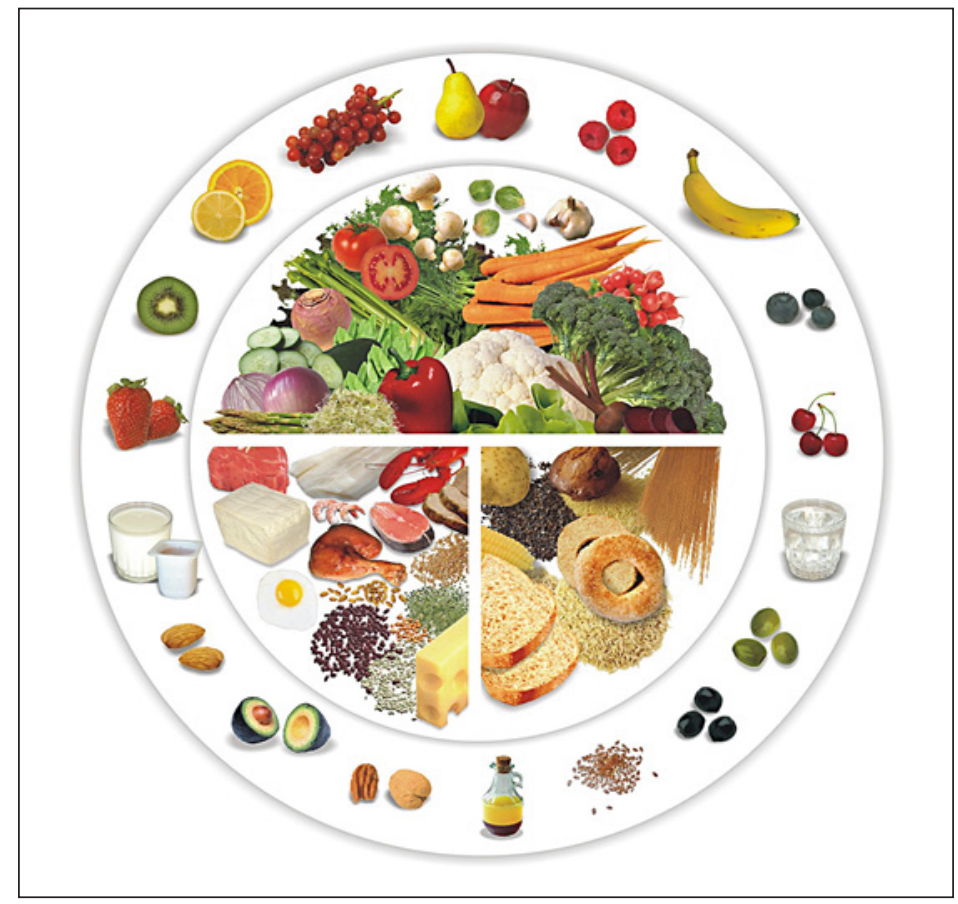

nuts, goat's cheese and mountain cheese. Rapeseed oil is also rich in omega- 3 fatty acid. The diet also includes olive oil and avocado. A meta-analysis on the Mediterranean diet significantly revealed an $8 \%$ reduction of death from all causes, a 10\% reduction from death and/ or incidence of cardio- and cerebrovascular diseases, a 6\% reduction from death and/or the incidence of neoplastic diseases and a 13\% reduction of the incidence of neurodegenerative diseases [37].

Physical Activity and Inactivity [8, 11, 39-45]

Today we consider that both physical activity and inactivity (i.e. doing insufficient physical activity in daily life) have to be dealt with in conjunction as both factors are interrelated: a net increase in physical activity will automatically decrease inactivity and vice versa, provided no compensation occurs.

An important message that can be given to the patient is that some recent studies and meta-analyses have shown that people with obesity who reached a high cardiorespiratory fitness have a lower mortality risk due to all aetiologies than normal-weight sedentary patients, namely those who sit or lie down for a prolonged period of time [39]. This message could be a motivation to increase physical activity in some patients. Moreover, the anatomical distribution of adipose tissue is very important: gynoid patients are protected from cardiometabolic disease by the subcutaneous adipose tissue (gluteal region). Visceral fat promotes cardiometabolic disease [40,41]. Regular physical activity mobilizes visceral fat and decreases the risks of comorbidities.

About $300 \mathrm{~min} /$ week of endurance activity at moderate intensity or $150 \mathrm{~min}$ of more intense activity is sufficient to mobilize visceral fat [39-41,43]. Physical activity can be split into multiple short segments of $10 \mathrm{~min}$ minimum in order to have a metabolic impact.

The general prescription for the population is at least of $150 \mathrm{~min} /$ week of moderate aerobic activity, equivalent to walking at 5-6 km/h. Doing sport is not crucial. Walking remains the best physical activity/exercise for both normal-weight/overweight and patients with obesity for the following reasons: 
1 It does not require specific equipment, except appropriate shoes

2 It can be done anywhere, free of charge

3 The patient can decide (self-tune) on the intensity of exercise as part of the self-determined adjustment of speed, selection of slopes (positive or negative grade) and a particular terrain (walking in snow/sand).

If a GP prescribes walking [44], $30 \mathrm{~min} /$ day (or $2 \times 15$ or $3 \times 10 \mathrm{~min}$ ) 5 days per week is an appropriate duration for overweight patients and patients with obesity. This prescription requires a progressive increase in volume and intensity of physical activity. When the total duration of exercise is longer than $30 \mathrm{~min}$ ( 60 or $90 \mathrm{~min}$ ), adherence to exercise may decrease and, as a double burden, compensation to the added exercise could occur, namely an increased placidity during the post-exercise period [44]. In order to increase total physical activity to $45 \mathrm{~min}$, about $60 \mathrm{~min}$ of walking should be prescribed, since compliance tends to diminish with the duration of exercise.

Physical activity can be combined with 2-3 sessions of resistance exercise at least twice a week comprising 8-10 exercises involving large muscle groups.

Some examples of adapted sports for patients with obesity are: swimming, aqua gymnastics, Nordic walking, cycling, dancing, judo, cross-country skiing, golf, hiking, table tennis, muscle strengthening and cardio training under supervision.

The aim is to decrease physical inactivity (sitting time) as well as increase physical activity (= replacement effect) and recover the pleasure of moving and being active as much as possible by selecting appropriate physical activity. Note that any strenuous exercise in a patient with obesity requires a cardiac assessment by a cardiologist using an exercise stress test [45]. Moderate workload (e.g. walking, non-competitive swimming etc.) does not require this test, except for patients with existing comorbidities, in particular type 2 diabetes.

A schematic diagram is shown in Figure 8, visualizing the guidelines in terms of the type of physical activity, its effects on body composition and its duration expressed as an average number of minutes each activity should be performed to maximize health.

Psychological Aspects [2-11]

Psychological factors are very important for obesity management and strongly influence the success of the treatment, in particular in individuals suffering from severe obesity (class III). Eating disorders such as binge eating, night eating syndrome and severe multiple snacking should be treated by a psychiatrist, a psychologist or an obesity specialist with cognitive behavioural therapy.

Generally, there is a close relationship between the emotional state and stressful situations on the one hand and the desire or need to eat on the other. Becoming aware of the emotional relationship with food is the basis of the treatment. The objective is to decrease eating compulsions and to find new strategies to answer and mitigate these emotions, managing emotions in other ways than eating. It is also important to discuss the patient's knowledge of food and nutrition.

Eating disorders are defined by DSM V $[46,47]$, comprising snacking and isolated or irregular compulsive disorders or binge eating, all of which are common in individuals suffering from obesity.

Binge eating disorder is defined as follows:

1 Ingestion of a very large quantity of food in a very limited period of time

2 Deep sensation of loss of control of eating behaviour during the binge (for example, feeling to be unable to stop eating)

3 The binge episodes are associated with 3 (or more) of the following characteristics:

- Eating far more quickly than usual (speed of eating)

- Eating excessively until a painful feeling of gastric distension occurs 


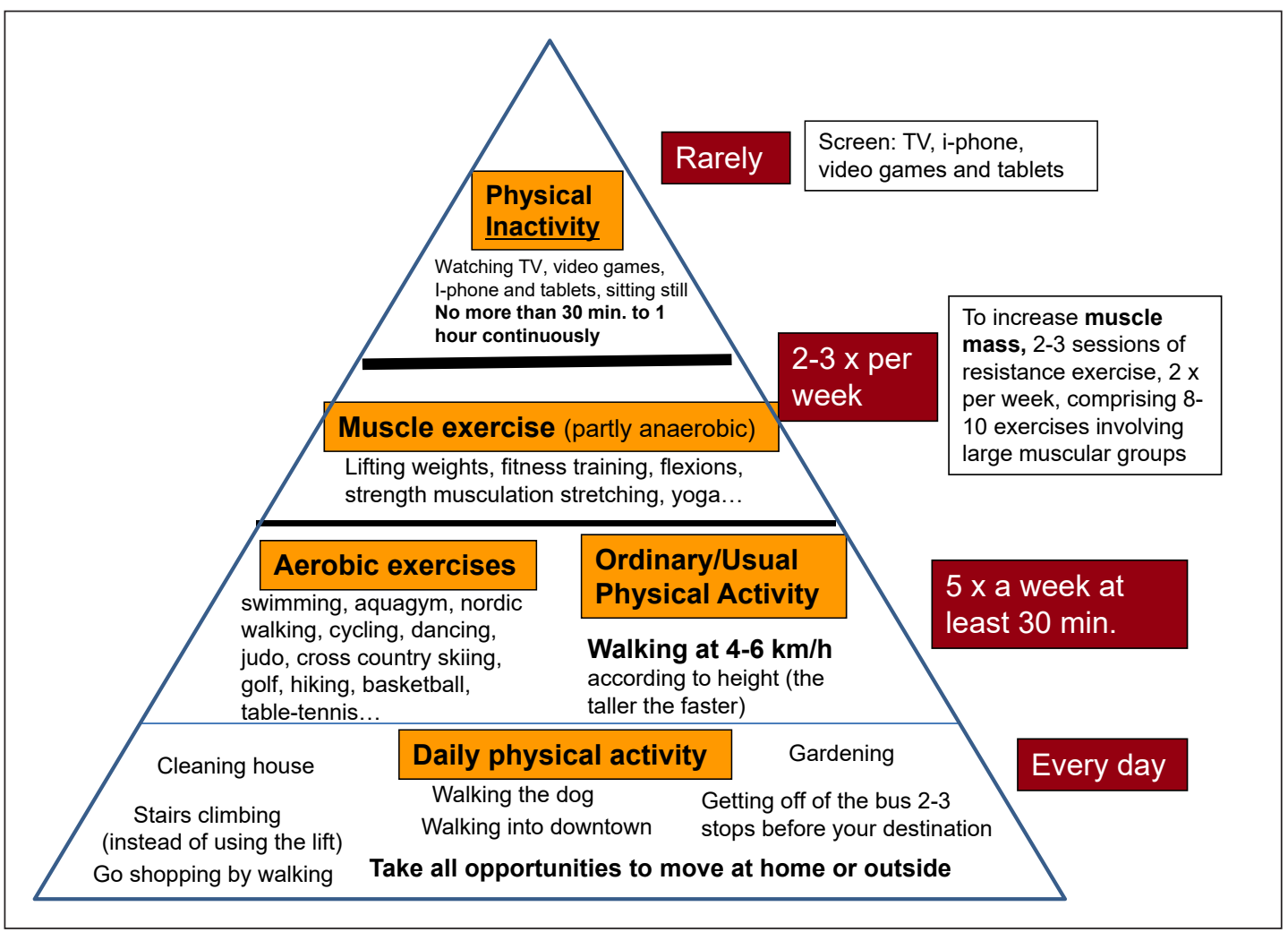

Fig. 8. The principle of the physical activity pyramid is that the more you climb the pyramid, the less amount of time needs to be dedicated to physical activity. This is because the intensity of exercise becomes gradually higher. The last level (at the top) constitutes the inactivity component, which must be taken into account, since the more time spent sedentary in daily life, the less time is available for exercise.

- Eating a large quantity of food without any sensation of hunger

- Eating in isolation because of the shame of eating so much and so quickly

- Feeling disgusted by oneself, depressed or guilty of the enormous amount of food which has been eaten in a short period of time

4 This binge is source of deep distress

5 This binge occurs at least twice a week for 6 months or more

6 This behaviour is not associated with inappropriate compensatory behaviours such as vomiting or compensatory exercises.

GPs may look for these disorders in the following sequences:

- First, hunger sensation, appetite and satiety or restrictive behaviour

- Then, snacking, compulsive eating, binge eating or night eating syndrome

- Patient's eating reactions towards positive or negative emotions

- Compensatory behaviours.

There is a positive relationship between the severity of the obesity and the occurrence of binge eating, as well as with weight cycling and depression.

The treatment of eating disorders should be managed by specialists (psychiatrists, psychologists). Cognitive behavioural therapy has shown good results [46]:

1 The first step is to increase the motivation to change using MI

2 The second is to restructure the meal pattern during the day: three meals a day, allowing breaks between meals to be able to discern the physiological sensation of hunger and satiety 
Durrer Schutz et al.: Management of Obesity by GPS

3 It is important not to restrict eating and to explore and learn to detect exogenous or endogenous stimuli which can lead to loss of control. Triggers are linked with food and emotions, such as being exposed to a person who is eating, forbidden food, skipping meals which leads to excess hunger, smelling food and feelings of stress, loneliness, boredom, inactivity, conflict, tiredness, sense of failure etc.

4 The patient will be helped to find his/her own strategies to avoid snacking or compulsive disorders and to identify the triggers related to emotion, to identify and express his/her emotions in other ways and to enjoy getting out of the house or kitchen

5 Finally, explore and identify automatic negative thoughts should be identified. The patient will learn to identify negative thoughts and put them in perspective, to deal with emotion in other ways than eating, to look for positive thoughts and to evaluate anxiety and depression.

Psychotherapy is often necessary to treat depression and anxiety. Body image, selfesteem and self-confidence may also be improved by psychotherapy. Art therapy, dance therapy, role playing, hypnosis and gestalt therapy can also help to enhance quality of life.

Patients suffering from a compulsive eating disorder have very low self-esteem, which is worsened by the loss of control and results in deep distress. So significant work can be done to improve body image, self-esteem, self-confidence, self-affirmation and quality of life in individual therapy or in group therapy.

\section{Pharmacotherapy $[2-8,48,49]$}

Anti-obesity drug therapy and drug therapy of comorbidities can complement lifestyle therapy but can never be used alone. Anti-obesity drugs are suitable for patients with BMI > $30 \mathrm{~kg} / \mathrm{m}^{2}$ or with BMI $>27 \mathrm{~kg} / \mathrm{m}^{2}$ with comorbidities. There are responders and nonresponders to the anti-obesity drugs. A $5 \%$ weight loss in non-diabetic patients and $>3 \%$ weight loss in diabetic patients should be achieved after 3-month treatment. If this is not the case, the anti-obesity drug should be interrupted. Weight loss drugs should not be used in pregnancy, lactation and childhood.

Today (in 2018), very few obesity drugs are available on the market: only 3 drugs received approval for clinical use in obesity management in Europe: orlistat, liraglutide and the combination of bupropion/naltrexone. The availability of these drugs varies within European countries, and they can be subjected to prescription limitations according to national rules.

- Liraglutide is a glucagon-like peptide 1 analogue (GLP-1). It is an incretin E (intestinal

hormone) which is secreted by the ileum in response to a meal. It belongs to the class of satiety hormones. It induces an increase of insulin secretion by the pancreas and sends a message of satiety to the brain. It is injectable and lasts about $24 \mathrm{~h}$. It is already used to treat type 2 diabetes with a dose of $0.8-1.8 \mathrm{mg} /$ day. A dosage of $3 \mathrm{mg}$ has been available on the market since 2015 for the treatment of obesity in Europe. It is generally well tolerated, except for side effects such as nausea and vomiting which may occur at the beginning of the treatment. In patients with cholelithiasis, it should be used with caution with a slower speed of weight loss and the addition of ursodeoxycholic acid [2].

- Orlistat is a potent and selective inhibitor of pancreatic lipase that reduces intestinal absorption of fat. The drug is available over the counter at a dose of $60 \mathrm{mg} /$ day and a prescription dosage of $120 \mathrm{mg} /$ day. Both forms are given before each (fatty) meal and produce a moderate absolute and placebo-subtracted weight loss. Faecal fat loss and related gastrointestinal symptoms (fatty diarrhoea) are common. It may cause small decreases in fat-soluble vitamins; thus a multivitamin complement can be prescribed [1]. 
Durrer Schutz et al.: Management of Obesity by GPS

Table 8. Comparison of the three major bariatric surgery procedures for the treatment of severe obesity

\begin{tabular}{lll}
\hline Gastric bypass & Gastric band (adjustable) & Sleeve gastrectomy \\
\hline Very long technical experience & Three decades of experience & One decade of experience \\
\hline $\begin{array}{l}\text { Stomach and small intestine bypassed and } \\
\text { stomach reduced to a very small pouch size }\end{array}$ & $\begin{array}{l}\text { Band placed around upper part of the } \\
\text { stomach (adjustable externally) }\end{array}$ & $\begin{array}{l}\text { Stomach restricted vertically } \\
\text { (80\% removed) }\end{array}$ \\
\hline $\begin{array}{l}\text { Food intake volume considerably reduced; } \\
\text { absorption of nutrients reduced }\end{array}$ & $\begin{array}{l}\text { Restricts food volume (variable as it is } \\
\text { voluntarily adjusted) }\end{array}$ & Restricts food volume \\
\hline $\begin{array}{l}\text { Massive weight loss expected } \\
\text { (14-20 units of BMI) }\end{array}$ & $\begin{array}{l}\text { Significant weight loss expected } \\
\text { (8-12 units of BMI) }\end{array}$ & Very significant weight loss \\
\hline Partly reversible procedure & Fully reversible procedure & Irreversible procedure
\end{tabular}

- Bupropion/naltrexone combines two centrally acting medications that have already been approved. Bupropion is used for treating depression and to aid smoking cessation. It is a nonselective inhibitor of dopamine and norepinephrine transporters. Naltrexone is an opioid receptor antagonist widely used to treat alcohol and opiate dependence syndromes. The anorectic effect of the bupropion/naltrexone combination is believed to result from a sustained activation of anorexigenic neurons in the hypothalamus. The recommended dosage is $16 \mathrm{mg}$ naltrexone / $180 \mathrm{mg}$ bupropion twice a day. The product licence requires $5 \%$ weight loss after 12 weeks of treatment. If a patient does not reach this target, the drug should be discontinued. The most common reported adverse event is nausea, which in most cases is transient for the first few weeks of treatment. Besides nausea, headache, dizziness, insomnia and vomiting are the most common adverse events that lead to discontinuation [2-10].

A comprehensive table summarizing the mechanism, contraindications, dosage and sideeffects of the various drugs used for obesity treatment in Europe has been published by Toplak et al. [48] in 2015 and in the European Guidelines for Obesity Management in Adults [2].

The presence of obesity and the effects that treatments have on body weight, body composition and metabolic status should be taken into account in the selection of drugs used to treat obesity-related comorbidities and non-obesity-related diseases occurring in a patient with obesity. Drugs increasing body weight and/or with negative metabolic effects should be possibly avoided or substituted. Weight loss and weight neutral medications should be preferred [2].

\section{Bariatric Surgery [2-10, 48, 50-59]}

Bariatric surgery is the most effective and efficient treatment for individuals suffering from severe obesity, in the middle and in the long term. The major health effects from bariatric surgery are related to inducing substantial weight loss and not to surgery per se [50]. However, it is the most invasive procedure to treat obesity and "it may not be appropriate for the majority of patients" [48]. Bariatric surgery is considered when conventional treatment over a certain duration has failed and if BMI is $>40 \mathrm{~kg} / \mathrm{m}^{2}$ or $>30 \mathrm{~kg} / \mathrm{m}^{2}$ with associated comorbidities, if BMI is $>35 \mathrm{~kg} / \mathrm{m}^{2}$ with comorbidities, or if BMI is $>30 \mathrm{~kg} / \mathrm{m}^{2}$ with type 2 diabetes on individual basis [2]. 
Fig. 9. Bariatric surgery, typically used for massive obesity treatment, requires continuous medical surveillance both before and after gastric surgery, irrespective of the surgical procedure used. The time scale for post-surgery management is virtually lifelong.

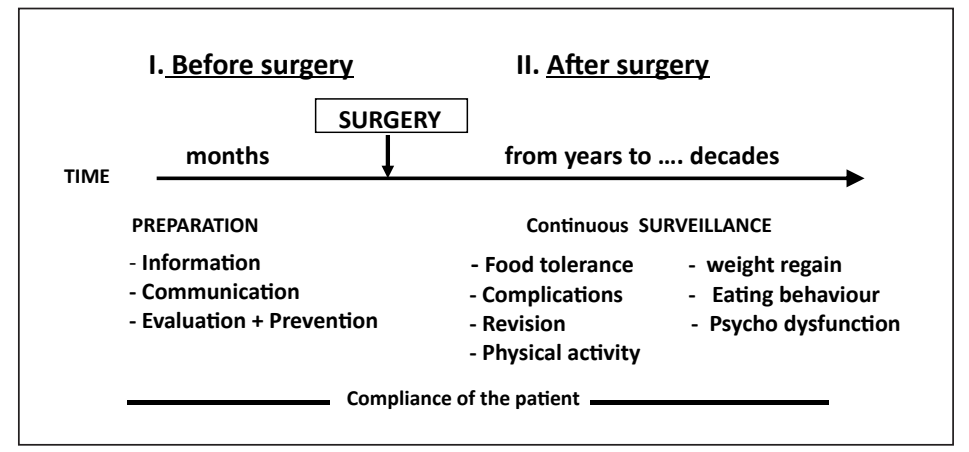

Patients with indications for bariatric surgery may be referred by GPs to specialized bariatric surgery centres, where they can be fully and objectively informed, fully psychologically prepared and treated by a dedicated and accredited multidisciplinary team [48]. In addition, their decision to undergo the operation should be made after a sufficient time of reflection.

A summary of the three major bariatric procedures is outlined in Table 8. The ranges of expected BMI losses for the three procedures have been taken from Bray et al. [59].

Bariatric patients require additional lifelong medical follow-up and management after surgery (Fig. 9). Eating habits need to be adapted to the new gastrointestinal physiology, and nutritional deficits often arise, depending on the type of bariatric procedure. The restriction of food intake after all bariatric surgery procedures as well as the malabsorption of nutrients induced by bypass procedures can cause long-term multiple nutritional deficiencies (e.g. proteins, several vitamins, minerals and trace elements). Therefore, long-term mineral and multivitamin supplements should be prescribed to every bariatric patient according to the surgery procedure used. In addition, periodic laboratory surveillance for nutritional deficiencies is recommended, and appropriate supplements will be individualized accordingly [57]. Patients with demonstrated micronutrient deficiencies will be treated with the respective micronutrient. Moreover, the management of obesity-associated diseases needs to be modulated according to weight loss. Specific problems may arise in patients who experience some psychological difficulties in adapting to the profound changes in eating behaviours and change in body image due to the huge amount of weight loss occurring within a year or more. Maintenance or relapse in food intake disturbances and eating disorders (which have not been treated by the operation) as well as psychological dysfunctions are often observed. Finally, relapse in body weight gain (of various magnitudes) generally occurs after a few years to a decade. There should be an early attempt at prevention through lifestyle modification, focusing particularly on physical activity and on eventual treatment with appropriate weight loss drugs [57].

The appropriate medical management of post-bariatric follow-up requires much attention. The provision of a post-bariatric multidisciplinary follow-up programme constitutes an integral part of the clinical pathway at bariatric surgery centres, and it will be offered to patients requiring it. However, part of the follow-up, particularly in the period directly after surgery, could also be carried out at primary care level (by GPs), provided these professionals have been trained specifically. The Obesity Management Task Force (OMTF) of the European Association for the Study of Obesity (EASO) recently released a paper containing practical recommendations for the post-bariatric surgery medical management [57]. 
Durrer Schutz et al.: Management of Obesity by GPS

Table 9. Schematic overview of the three different obesity managements

\begin{tabular}{|c|c|c|}
\hline Lifestyle modification & Pharmacotherapy & Bariatric surgery \\
\hline $\begin{array}{l}\text { Non invasive } \\
\text { Involves changes in: } \\
\text { Lifestyle and behaviour } \\
\text { Eating behaviour } \\
\text { Energy intake } \\
\text { Physical activity } \\
\text { Physical inactivity } \\
\text { Psychological aspects } \\
\text { Eating disorders } \\
\text { Stress } \\
\text { Depression } \\
\text { Body image } \\
\text { Self-esteem } \\
\text { Self-affirmation } \\
\text { Self-confidence } \\
\text { Quality of life }\end{array}$ & $\begin{array}{l}\text { Semi-invasive } \\
\text { Problems: } \\
\text { Limited choice of drugs } \\
\text { Small additional weight loss } \\
\text { Lacking long-term experience } \\
\text { Tolerance effects of drugs }\end{array}$ & $\begin{array}{l}\text { Invasive } \\
\text { Characteristics and problems: } \\
\text { 3-4 types of procedures } \\
\text { Significant, quick weight loss } \\
\text { Complications (10-30\%) } \\
\text { Reoperation ("revision") } \\
\text { Excess skin surgery } \\
\text { Patients often still obese after weight } \\
\text { loss if very high baseline BMI } \\
\text { Need lifestyle modification/pharmaco- } \\
\text { therapy after weight loss to minimize } \\
\text { weight regain }\end{array}$ \\
\hline
\end{tabular}

\section{Summary}

For a comprehensive view of the different obesity treatments described above, a schematic summary concerning lifestyle and behavioural therapy, pharmacotherapy and bariatric/ metabolic surgery, is shown in Table 9.

What are the important points to ensure successful treatment of obesity $[2-10,60,61]$ ?

1 Avoiding stigmatization from GPs, nurses, psychologists, psychiatrists, dietitians, nutritionists, obesity specialists and their teams, using appropriate language and communication techniques (motivational interviewing) and appropriate tools (cuff size, scales, discreet room to weigh the patient, chairs without armrests etc.)

2 Using motivational interviewing to increase patient's motivation to change and patient's confidence in the therapists as well as in the treatment, and to increase self-confidence to succeed with lifestyle modifications

3 Improving knowledge, adherence to treatment, motivation to change and quality of life through therapeutic patient education

4 Investigating psychological aspects such as eating disorders, sleep disorders, stress, depression and treating them specifically

5 Looking out for metabolically healthy patients with obesity and encouraging lifestyle modifications to keep them metabolically healthy as long as possible

6 Improving body composition (decreasing fat mass with minimal fat-free mass mobilization) through lifestyle modification, in particular enhanced general physical activity

7 Treating any comorbidities with lifestyle modification and pharmacotherapy if necessary

8 Envisaging pharmacologic treatment and bariatric surgery if lifestyle modifications and behavioural treatment have failed and if this is the last option available

9 Treatment could be considered a success if a patient with obesity has changed lifestyle in the long term, improved body composition, decreased comorbidities or is still metabolically healthy, stabilized weight or has reached a weight loss of $5-10 \%$ from initial weight, improved body image, self-esteem, self-confidence, self-affirmation and quality of life and has sufficient motivation to sustain lifestyle modification in the long term. 
Durrer Schutz et al.: Management of Obesity by GPs

A condensed, well-illustrated version of the present GPs' guidelines, in the form of a practical leaflet, is freely available for the public at the EASO website (http://easo.org/practicalguide-for-gps-in-obesity-management/, accessed October 2018).

In brief, there are 9 key practical messages for the management of adult obesity, including communication, motivation and therapeutic patient education, as well as the different treatment approaches:

1 Discuss the patient's personal situation with them after having collected all pertinent results, estimating cardiometabolic risks and evaluating other risk factors

2 Estimate the patient's degree of motivation and help them make the best choices about the amount of body weight loss, remembering that modest slimming (e.g. 3-5\% from initial body weight) is beneficial for health

3 Evaluate your patient's understanding and identify the potential obstacles to reaching the objectives

4 Together with the patient, develop a calendar and set and promote realistic goals which are based primarily on body composition change (fat mass loss) and a decrease in waist circumference rather than on body weight loss per se

5 Regarding the treatment, the first objective of treatment is to stabilize body weight. The GP may monitor weight loss and waist circumference every 1-2 weeks during the first months to evaluate the efficiency of the treatment plan with the patient and to progress step by step. "If there is no weight loss (less than $1 \%$ body weight or no change in waist circumference) after 3 months of active management, lifestyle behaviours and causes of weight gain should be reviewed" [6]. After 6 months, monitoring once a month may be sufficient. The GP can ask to the patient how frequently they want to have the consultations

6 With the patient, select their favourite specific area (physical activity and inactivity, nutrition or eating behaviour, psychological aspects, stress, etc.) to initiate obesity management. All these procedures may be supported by motivational interviewing and other therapeutic patient education techniques

7 Treating comorbidities first is important, irrespective of the amount of weight loss

8 After weight loss, particular attention must be given to avoiding weight cycling (yo-yo effect), and the patient must be clearly informed about the risk of weight regain

9 "Long-term weight management may be more successful if it involves a self-management approach, continuing contact with health care professionals and behavioural strategies for maintaining motivation. Self-management strategies for long-term weight management may include maintaining a healthy lifestyle, identifying ways to manage hunger, setting and reviewing goals, and regular self-weighing" [6].

\section{Prevention of Obesity Is Also Important}

Primary prevention measures are fundamental to controlling and moderating the development of obesity as early as possible in the natural history of obesity. We believe that GPs also play an essential role in prevention during the management of (pre)obesity. The targets for prevention in general practice have been published $[6,8]$. Three categories of prevention, primary, secondary and tertiary, plus a fourth (quaternary prevention) are presented in Figure 10. GPs play a central role in particular in quaternary prevention, in which the main objective is to identify a patient at risk of over-medicalization and to propose interventions which are ethically acceptable $[62,63]$. It also includes preventing stigmatization, avoiding the use of inappropriate medical treatment and management objectives and preventing "magical" (i.e. non-evidence-based) interventions/surgical approaches. 


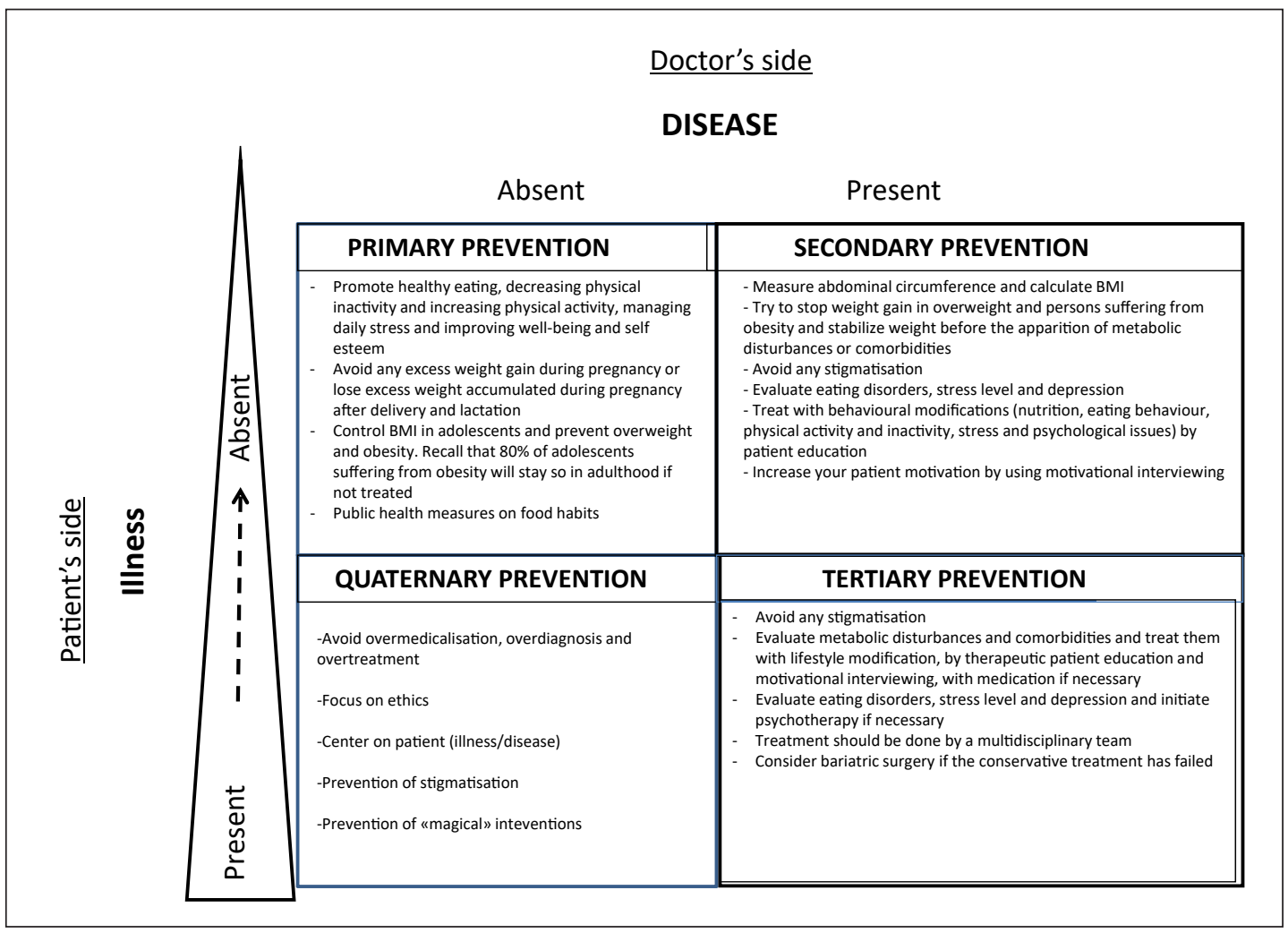

Fig. 10. Primary, secondary, tertiary and quaternary preventions with their respective explanations. The quaternary prevention is a new paradigm important to how GPs manage obesity. It is defined as actions taken by GPs to protect the patients from medical interventions that are likely to cause "more harm than good." Adapted from [67].

\section{Conclusions and Perspective}

GPs are the cornerstone of obesity management. They are the first to evaluate patients, diagnose obesity and treat comorbidities. They are an indispensable part of the obesity team and play a crucial role in comprehensive and continuous care. Ideally, the first task of GPs is to prevent obesity. Primary prevention of obesity is essential as, when it is established, obesity is complex, difficult and costly to treat. Public health regulation is also important to tackle because of strong economic and environmental influences such as the commercial promotion of foods high in fat and sugar. Moreover, the longer a patient suffers from obesity, the more difficult the patient is to treat. The patient is considered a partner and his/her own expert, playing a central role in treatment decisions. He/she is handled with respect, consideration and without stigmatization. If available, an inter- and multidisciplinary team including GPs, obesity experts, nutritionists/dietitians, psychologists/psychiatrists, physical activity specialists and nurses, appears to be the most efficient way of treating obesity today.

Recently, collaborative obesity centres for obesity management (COMs) [64] have been developed in Europe (under the EASO scheme) to assure the quality of obesity management. A number of European reference centres have been selected, and they have been trained to manage complex obesity cases.

Finally, the management of chronic diseases by GPs is paradoxically associated with a low level of evidence-based care [65]. As a result, the authors fully acknowledge that not all GPs 
Durrer Schutz et al.: Management of Obesity by GPS

may be able to strictly and thoroughly follow all recommendations set out in this paper, due to time constraints or other factors. Instead, they may individually select the necessary and relevant information available based on their own view, judgement and "philosophy" related to obesity management. Whilst the authors encourage the ideas around communication particularly to be adopted across Europe, we fully acknowledge that some countries already have obesity guidelines specific to their models of obesity service provision and which may reflect different GP role expectations, for example, where GPs have an awareness raising and signposting role, rather than obesity management role.

\section{Author Contributions}

D.DS conceived of the original idea and wrote the manuscript with Y.S. , who has supervised the project and provided and conceived most of the figures. The remaining authors, who contributed in a similar way, were ranked in alphabetical order: L.B., D.D., N.F-L., R.P., H.T., D.W., V.Y.

\section{Acknowledgements}

We are very grateful to Euan Woodward (EASO director) for his revision contribution to this article as well as to EASO for supporting publication costs.

\section{Disclosure Statement}

The authors have no conflicts of interest to declare.

\section{References}

1 Collaboration NC; NCD Risk Factor Collaboration (NCD-RisC). Worldwide trends in body-mass index, underweight, overweight, and obesity from 1975 to 2016: a pooled analysis of 2416 population-based measurement studies in 128.9 million children, adolescents, and adults. Lancet. 2017 Dec;390(10113):2627-42.

2 Yumuk V, Tsigos C, Fried M, Schindler K, Busetto L, Micic D, et al.; Obesity Management Task Force of the European Association for the Study of Obesity. European guidelines for obesity management in adults. Obes Facts. 2015;8(6):402-24.

3 Garvey WT, Mechanick JI, Brett EM, Garber AJ, Hurley DL, Jastreboff AM, Nadolsky K, Pessah-Pollack R, Plodkowski R; Reviewers of the AACE/ACE Obesity Clinical Practice Guidelines. American Association of Clinical Endocrinologists and American College of Endocrinology Comprehensive Clinical Practice Guidelines for Medical Care of Patients with Obesity. Endocr Pract. 2016 Jul;22 Suppl 3:1-203.

4 National Institutes of Health. The Practical Guide: Identification, Evaluation, and Treatment of Overweight and Obesity in Adults. NHLBI Obesity Education Initiative Expert Panel on the Identification, Evaluation, and Treatment of Overweight and Obesity in Adults. Bethesda, NIH, 2000. www.nhlbi.nih.gov/files/docs/guidelines/prctgd_c.pdf (accessed November 30, 2015)

5 Jensen MD, Ryan DH, Apovian CM, Ard JD, Comuzzie AG, Donato KA, et al.; American College of Cardiology/ American Heart Association Task Force on Practice Guidelines. Obesity Society: 2013 AHA/ACC/TOS Guideline for the Management of Overweight and Obesity in Adults: a report of the American College of Cardiology/ American Heart Association Task Force on Practice Guidelines and The Obesity Society. Circulation 2014; 129 suppl 2: S102-S138. Erratum in Circulation. 2014;129 suppl 2:S139-40.

6 Australian National Health and Medical Research Council, Summary Guide for the Management of Overweight and Obesity in Primary Care, Dec 2013. https://nhmrc.gov.au/sites/default/files/documents/reports/ clinical\%20guidelines/n57b-obesity-guidelines-summary.pdf (accessed December 18, 2018)

7 Fitzpatrick SL, Wischenka D, Bradley MA, Appelhans M, Pbert L, Wang M, Wilson DK, Pagoto SL, on behalf of the Society of Behavioral Medicine. An Evidence-Based Guide for Obesity Treatment in Primary Care. Am J Med. 2016 Jan; 129(1):115.e1-7. 
Durrer Schutz et al.: Management of Obesity by GPS

8 Swiss Consensus for Obesity Management. 2016, http//:www.sgedssed.ch/consensus-obesité (in French and German, accessed Dec. 2017)

9 Stegenga H, Haines A, Jones K, Wilding J; Guideline Development Group. Identification, assessment, and management of overweight and obesity: summary of updated NICE guidance. BMJ. 2014 Nov;349 nov27 2:g6608.

10 Hauner H, Buchholz G, Hamann A, Husemann B, Koletzko B, Liebermeister H, et al. (Adipositas-Gesellschaft D, Diabetes-Gesellschaft D, editors). Prevention and Treatment of Obesity, Evidence-based Guideline of the DDG. Deutsche. Gesellschaft für Ernährung, Deutsche Gesellschaft für Ernährungsmedizin; 2007.

11 Durrer D, Schutz Y. Obesite, les outils pour le praticien. Ed. Medecine \& Hygiene; 2008.

12 Puhl R, Heuer CA. The stigma of obesity: a review and update. Obesity (Silver Spring). 2009 May;17(5):941-64.

13 Flint S. Obesity stigma: prevalence and impact in healthcare. Br J Obes. 2015;1:14-8.

14 Poustchi Y, Saks NS, Piasecki AK, Hahn KA, Ferrante JM. Brief intervention effective in reducing weight bias in medical students. Fam Med. 2013 May;45(5):345-8.

15 Bucher Della Torre S, Courvoisier DS, Saldarriaga A, Martin XE, Farpour-Lambert NJ. Knowledge, attitudes, representations and declared practices of nurses and physicians about obesity in a university hospital: training is essential. Clin Obes. 2018 Apr;8(2):122-30.

16 Rollnick S, Miller WR, Butler CC. Motivational Interviewing in Health Care: Helping Patients Change Behavior. New York, Guildford Press, 2008

17 Armstrong MJ, Mottershead TA, Ronksley PE, Sigal RJ, Campbell TS, Hemmelgarn BR. Motivational interviewing to improve weight loss in overweight and/or obese patients: a systematic review and meta-analysis of randomized controlled trials. Obes Rev. 2011 Sep;12(9):709-23.

18 Christie D, Channon S. The potential for motivational interviewing to improve outcomes in the management of diabetes and obesity in paediatric and adult populations: a clinical review. Diabetes Obes Metab. 2014 May; 16(5):381-7.

19 Talking with patients about weight loss: tips for primary care providers NIDDK (https://www.niddk.nih.gov)

20 http://www.hneccphn.com.au/media/14254/nh-and-mrc-obesity_guidelines_summary_guide_131219.pdf

21 WHO. Physical status: the use of anthropometry, report of WHO Expert Committee, WHO Technical Report Series 854, Geneva, WHO, 1995

22 Flicke L, McCaul K, Hankey GJ, Jamrozik K, Brown WJ, Byles JE, Almeida OP. Body Mass Index and Survival in Men and Women Aged 70 to 75. J Am Geriatr Soc. 2010 Feb;58(2):234-41

23 Zhu S, Wang Z, Heshka S, Heo M, Faith MS, Heymsfield SB. Waist circumference and obesity-associated risk factors among whites in the third National Health and Nutrition Examination Survey: clinical action thresholds. Am J Clin Nutr. 2002 Oct;76(4):743-9.

24 Manolopoulos KN, Karpe F, Frayn KN. Gluteofemoral body fat as a determinant of metabolic health. Int J Obes. 2010 Jun;34(6):949-59.

25 Ortega FB, Lee D-C, Katzmarzyk P, Ruiz J, Sui X, Church T, Blair S. The intriguing metabolically healthy but obese phenotype: cardiovascular prognosis and role of fitness. Eur Heart J. 2013 Feb;34(5):389-97.

26 Finer N. Medical consequences of obesity. Medicine (Baltimore). 2015;43(2):88-93.

27 Sampsel S, May J. Assessment and management of obesity and comorbid conditions. Dis Manag. 2007 Oct; 10(5):252-65.

28 Huang PL. A comprehensive definition for metabolic syndrome. Dis Model Mech. 2009 May-Jun;2(5-6):231-7.

29 Lagger G, Pataky Z, Golay A. Efficacy of therapeutic patient education in chronic diseases and obesity, Patient education and counseling. Patient Educ Couns. 2010 Jun;79(3):283-6.

30 Golay A, Giordan A. Guide d'education therapeutique du patient. Paris, Editions Maloine; 2015.

31 Munsch S, Biedert E, Keller U. Evaluation of a lifestyle change programme for the treatment of obesity in general practice. Swiss Med Wkly. 2003 Mar;133(9-10):148-54.

32 Wadden TA, Webb VL, Moran CH, Bailer BA. Lifestyle modification for obesity: new developments in diet, physical activity, and behavior therapy [Review]. Circulation. 2012 Mar;125(9):1157-70.

33 Skolnik NS, Horn DB. Answers to Clinical Questions in the Primary Care Management of People with Obesity: lifestyle Management. J Fam Pract. 2016 Jul;65(7 Suppl):S13-6.

34 Sharma M. Behavioural interventions for preventing and treating obesity in adults. Obes Rev. 2007 Sep;8(5): 441-9.

35 Lang A, Froelicher ES. Management of overweight and obesity in adults: behavioral intervention for long-term weight loss and maintenance. Eur J Cardiovasc Nurs. 2006 Jun;5(2):102-14.

36 Daly P, Pace T, Berg J, Menon U, Szalacha LA. A mindful eating intervention: A theory-guided randomized antiobesity feasibility study with adolescent Latino females. Complement Ther Med. 2016 Oct;28:22-8

37 Sofi F, Abbate R, Gensini GF, Casini A. Accruing evidence on benefits of adherence to the Mediterranean diet on health: an updated systematic review and meta-analysis. Am J Clin Nutr. 2010 Nov;92(5):1189-96.

38 Physical Activity Promotion in Primary Care. www.paprica.ch

39 Donnelly JE, Blair SN, Jakicic JM, Manore MM, Rankin JW, Smith BK; American College of Sports Medicine. American College of Sports Medicine Position Stand. Appropriate physical activity intervention strategies for weight loss and prevention of weight regain for adults. Med Sci Sports Exerc. 2009 Feb;41(2):459-71.

40 Lee CD1, Blair SN, Jackson AS. Cardiorespiratory fitness, body composition, and all-cause and cardiovascular disease mortality in men. Am J Clin Nutr. 1999 Mar;69(3):373-80. 
41 Hu G, Tuomilehto J, Silventoinen K, Barengo NC, Peltonen M, Jousilahti P. The effects of physical activity and body mass index on cardiovascular, cancer and all-cause mortality among 47212 middle-aged Finnish men and women. Int J Obes. 2005 Aug;29(8):894-902.

42 Willis LH, Slentz CA, Bateman LA, Shields AT, Piner LW, Bales CW, et al. Effects of aerobic and/or resistance training on body mass and fat mass in overweight or obese adults. J Appl Physiol (1985). 2012 Dec;113(12): 1831-7.

43 Kay SJ, Fiatarone Singh MA. The influence of physical activity on abdominal fat: a systematic review of the literature. Obes Rev. 2006 May;7(2):183-200.

44 Schutz Y, Nguyen DM, Byrne NM, Hills AP. Effectiveness of three different walking prescription durations on total physical activity in normal- and overweight women. Obes Facts. 2014;7(4):264-73.

45 American College of Sports Medicine; American Heart Association. Exercise and acute cardiovascular events: placing the risks into perspective. Med Sci Sports Exerc. 2007 May;39(5):886-97.

46 Spitzer RL1, Yanovski S, Wadden T, Wing R, Marcus MD, Stunkard A, Devlin M, Mitchell J, Hasin D, Horne RL. Binge eating disorder: its further validation in a multisite study. Int J Eat Disord. 1993 Mar;13(2):137-53.

47 Regier DA, Kuhl EA, Kupfer DJ. The DSM-5: classification and criteria changes. World Psychiatry. 2013 Jun; 12(2):92-8.

48 Toplak H, Woodward E, Yumuk V, Oppert JM, Halford JC, Frühbeck G. 2014 EASO position statement on the use of anti-obesity drugs. Obes Facts. 2015;8(3):166-74.

49 Jordan J, Nilsson P, Kotsis V, Olsen M, Grassi G, Yumuk V, Hauner H, Zahorska-Markiewicz B, Toplak H, Engeli S, Finer N. Joint scientific statement of the European Association for the Study of Obesity and the European Society of Hypertension: obesity and early vascular ageing., J Hypertens. 2015 Mar;33(3):425-34.

50 Livingston EH. Reimagining Obesity in 2018: A JAMA Theme Issue on Obesity. JAMA. 2018 Jan;319(3):238-40.

51 Arterburn DE, Courcoulas AP. Bariatric surgery for obesity and metabolic conditions in adults. BMJ. 2014 Aug; 349:g3961.

52 Fried M, Yumuk V, Oppert JM, Scopinaro N, Torres AJ, Weiner R, et al.; European Association for the Study of Obesity; International Federation for the Surgery of Obesity - European Chapter. Interdisciplinary European guidelines on metabolic and bariatric surgery. Obes Facts. 2013;6(5):449-68.

53 Swiss Medical Board. Bariatric surgery vs. conservative treatment for obesity and overweight. http://www. medicalboard.ch/fileadmin/docs/public/mb/berichte/20161018_appraisal_report_bariatric_surgery.pdf. DOI: 10.13140/RG.2.1.2195.8804.

54 Gloy VL, Briel M, Bhatt DL, Kashyap SR, Schauer PR, Mingrone G, et al. Bariatric surgery versus non-surgical treatment for obesity: a systematic review and meta-analysis of randomised controlled trials. BMJ. 2013 Oct 22;347:f5934.

55 Sjöström L. Review of the key results from the Swedish Obese Subjects (SOS) trial - a prospective controlled intervention study of bariatric surgery. J Intern Med. 2013 Mar;273(3):219-34.

56 Haute Autorité de Santé (HSA). Obésité: prise en charge chirurgicale chez l'adulte. 2009. http://www.hassante.fr/portail/jcms/c_765529/fr/obesite-prise-en-charge-chirurgicale-chez-l-adulte. Accessed July 27, 2016

57 Busetto L, Dicker D, Azran C, Batterham RL, Farpour-Lambert N, Fried M, et al.; Practical Recommendations of the Obesity Management Task Force of the European Association for the Study of Obesity for the PostBariatric Surgery Medical Management. Practical Recommendations of the Obesity Management Task Force of the European Association for the Study of Obesity for the Post-Bariatric Surgery Medical Management. Obes Facts. 2017;10(6):597-632.

58 Fried M, Hainer V, Basdevant A, Buchwald H, Deitel M, Finer N, et al. Interdisciplinary European guidelines on surgery of severe obesity. Obes Facts. 2008;1(1):52-9.

59 Bray GA, Frühbeck G, Ryan DH, Wilding JP. Management of obesity. Lancet. 2016 May;387(10031):1947-56.

60 Marchesini G, Cuzzolaro M, Mannucci E, Dalle Grave R, Gennaro M, Tomasi F, et al.; QUOVADIS Study Group. Weight cycling in treatment-seeking obese persons: data from the QUOVADIS study. Int J Obes Relat Metab Disord. 2004 Nov;28(11):1456-62.

61 Anderson JW, Konz EC, Frederich RC, Wood CL. Long-term weight-loss maintenance: a meta-analysis of US studies. Am J Clin Nutr. 2001 Nov; 74(5):579-84.

62 Widmer D, Herzig L, Jamoulle M. [Quaternary prevention: is acting always justified in family medicine?]. Rev Med Suisse. 2014 May;10(430):1052-6.

63 Albert K, Kuehlein T, Schedlbauer A, Schaffer S. Medical overuse and quaternary prevention in primary care - A qualitative study with general practitioners. BMC Fam Pract. 2017 Dec 8;18(1):99.

64 Tsigos C, Hainer V, Basdevant A, Finer N, Fried M, Mathus-Vliegen E, et al.; Obesity Management Task Force of the European Association for the Study of Obesity. Management of obesity in adults: european clinical practice guidelines. Obes Facts. 2008;1(2):106-16.

65 Homa L, Rose J, Hovmand PS, Cherng ST, Riolo RL, Kraus A, et al. A participatory model of the paradox of primary care. Ann Fam Med. 2015 Sep;13(5):456-65.

66 Schutz Y, Sarafian D, Miles JL, Montani JP, Dulloo AG. Non-contact assessment of waist circumference: will tape measurements become progressively obsolete? Eur J Clin Nutr. 2012 Feb;66(2):269-72.

67 Jamoulle M. Quaternary prevention, an answer of family doctors to overmedicalization. Int J Health Policy Manag. 2015 Feb;4(2):61-4. 